\title{
Novolac phenolic resin and graphene aerogel organic- inorganic nanohybrids: high carbon yields by resin modification and its incorporation into aerogel network
}

\author{
Akbar Noparvar-Qarebagh ${ }^{1}$, Hossein Roghani-Mamaqani ${ }^{1,2 *}$, Mehdi Salami-Kalajahi ${ }^{1,2 *}$ \\ ${ }^{1}$ Department of Polymer Engineering, Sahand University of Technology, P.O. Box 51335-1996, \\ Tabriz, Iran. \\ ${ }^{2}$ Institute of Polymeric Materials, Sahand University of Technology, P.O. Box 51335-1996, \\ Tabriz, Iran.
}

\section{ABSTRACT}

Graphene oxide (GO) modified with furfuryl alcohol and (3-aminopropyl) triethoxysilane (GOFASi) was used in two separate ways for preparation of novolac resin nanohybrids. In the first procedure, graphene-containing silica aerogel (GA) was obtained by incorporation of GOFASi into silica aerogel network using tetraethyl orthosilicate (TEOS). Then, GA was used as an additive in novolac resin matrix. In the second procedure, the synthesis of a hybrid novolac resin was accomplished by network formation via the reaction of GOFASi with (3-

\footnotetext{
* Corresponding authors: Tel/Fax: +98 411 3459104. E-mail addresses: r.mamaghani@sut.ac.ir (H. Roghani-Mamaqani) and m.salami@sut.ac.ir (M. Salami-Kalajahi)
} 
glycidyloxypropyl)trimethoxysilane-modified novolac resin and TEOS. The thermal stability and the carbon yield of the hybrid resins obtained by the two procedures were compared. Fourier transform infrared spectroscopy, X-ray photoelectron spectroscopy, and thermogravimetric analysis showed that both GO and the novolac resin were successfully modified. Aerogel formation was proved by Raman, $\mathrm{X}$-ray diffraction, $\mathrm{N}_{2}$ adsorption and desorption isotherms, and by scanning and transmission electron microscopies.

Keywords: Novolac phenolic resin; Graphene aerogel; Carbon yield. 


\section{Introduction}

Organic-inorganic hybrid materials have been have been extensively studied in the past few decades because of their unique properties. Polymer matrices can be improved remarkably in their thermal, mechanical, physical, and other characteristics by incorporation of metal oxide clusters via various coupling agents [1-3]. Content of additive, its dispersion uniformity, and interaction with the host polymer matrix are important factors in properties of such products. These hybrid materials were commonly prepared via sol-gel process, which provides the possibility of polymer chains incorporation into silica domains. Inorganic domains are mainly formed from the hydrolysable multifunctional alkoxysilanes. Interconnected networks are formed by using appropriate coupling agents which provide covalent bonding between a polymer matrix and inorganic domains.

Sol-gel process is commonly used for synthesis of silica-based mesoporous materials known as aerogels. Silica aerogels because of high porosity, large pore volume, low density, and high surface area were commonly used as thermal and acoustic insulators in hybrid composites with polymers [4, 5]. Microstructure of aerogels is constructed by hydrolysis and condensation processes, which mainly controlled by $\mathrm{pH}$ of the reaction medium. At lower $\mathrm{pH}$ values, higher hydrolysis rates results in a highly extended network structures. In contrast, higher condensation rates results in a highly condensed structures at higher $\mathrm{pH}$ values [6]. In addition to $\mathrm{pH}$, alkoxide type, water amount, temperature, and drying methods are the other important factors in microstructure of aerogels.

Reinforcement of silica aerogels was previously carried out by multifunctional coupling agents of alkoxysilanes [7]. Also, alkoxysilanes were used to incorporate SWCNT and graphene into the silica aerogel network for improving its mechanical properties [8, 9]. However, preparation 
of graphene aerogels with high surface area and low density were reported by hydrothermal [1011], resorcinol and formaldehyde sol-gel polycondensation [12], and chemical reduction methods [13-15]. Self-assembly of graphitic layers into three-dimensional aerogel structure is observed in these methods, which prevents from restacking of layers in various polymer matrices. The latter is very attractive because of its simple reaction conditions and no requirement of binder moieties. It is noteworthy that preparation of carbon nanotube and graphene-carbon nanotube aerogels were also reported [16-19].

Phenolic resins were commonly synthesized from the source of a phenol and an aldehyde in two forms of resol and novolac, which is different in phenol and formaldehyde ratio and also type of the acidic or basic catalyst. Phenolics can be used in ablative thermal protection applications as thermal resistant thermosets. Structural modification of phenolics results in high thermal stability and high carbon yield values upon pyrolysis in nitrogen (TGA). Incorporation of boron and phosphorous moieites [20-24] and inorganic modifiers [6, 25-26] into the phenolics structure are some important examples of structural modification methods. Additionally, thermal properties of phenolics were improved by the addition of graphene and carbon nanotube as carbon fillers [27-30].

In this study, phenolic resin structural modification with inorganic silane moieties by sol-gel process, incorporation of silane- and furfuryl alcohol-modified graphene and silane-modified phenolic resin into a silica network, and addition of GA into phenolic resin has been considered to increase the thermal properties and carbon yields of phenolic resin products. Herein, GA has been prepared by a sol-gel process. Also, graphene and phenolic resin formed a network by a solgel process similar to GA. Silane coupling agents of (3-glycidyloxypropyl) trimethoxysilane (GPTES) for phenolic resin and (3-aminopropyl) triethoxysilane (APTES) for furfuryl alcohol- 
modified graphene were used to increase phenolic resin and graphene compatibility and also network formation. This can also result in lowering phase separation between the organic and inorganic media. Designation of samples is given in Table 1.

Table 1- Designation of the samples

\begin{tabular}{|c|c|}
\hline Sample & Description \\
\hline APTES & (3-aminopropyl) triethoxysilane \\
\hline GPTES & (3-glycidyloxypropyl) trimethoxysilane \\
\hline G & graphite \\
\hline GO & furfuryl alcohol-functionalized GO oxide \\
\hline GOFA & APTES-functionalized GOFA \\
\hline GOFASi & graphene-containing silica aerogel \\
\hline GA & silica aerogel \\
\hline SA & novolac resin \\
\hline R & GOFASi/MR cured composite with X wt\% of GOFASi \\
\hline MR & GPTES-functionalized R \\
\hline CR & Cured R \\
\hline RGAX & \\
\hline
\end{tabular}

\section{Experimental}

\subsection{Materials}

Novolac resin (IP502, Resitan), graphite (Merck), potassium permanganate $\left(\mathrm{KMnO}_{4}\right.$, SigmaAldrich, 99\%), sodium nitrate $\left(\mathrm{NaNO}_{3}\right.$, Sigma-Aldrich, 99\%), sulfuric acid $\left(\mathrm{H}_{2} \mathrm{SO}_{4}\right.$, Merck), 
furfuryl alcohol (Sigma-Aldrich, 98\%), N,N'-dicyclohexylcarbodiimide (DCC, Aldrich, 99\%), 4dimethylaminopyridine (DMAP, Aldrich, 99\%), (3-aminopropyl) triethoxysilane (APTES, Sigma-Aldrich, 99\%), tetraethoxysilane (TEOS, Merck), (3-glycidyloxypropyl) trimethoxysilane (GPTES, Aldrich, 99\%), hexamethyldisilazane (Aldrich, 99\%), and hexamethyltetramine (HMTA, Sigma-Aldrich, 99\%) were used as received.

\subsection{Oxidation of graphite to prepare graphene oxide (GO)}

Modified Hummers' method was used for preparation of GO [31]. Accordingly, graphite (3.0 g) and $\mathrm{NaNO}_{3}(1.5 \mathrm{~g})$ were mixed with $\mathrm{H}_{2} \mathrm{SO}_{4}(180 \mathrm{~mL})$ in a $300-\mathrm{mL}$ flask for $15 \mathrm{~min}$ at room temperature. Subsequently, $\mathrm{KMnO}_{4}(9.0 \mathrm{~g})$ was slowly added to the flask and stirring was continued at $35{ }^{\circ} \mathrm{C}$ for $7 \mathrm{~h}$. After addition of the second part of $\mathrm{KMnO}_{4}(9.0 \mathrm{~g})$, stirring was continued for $12 \mathrm{~h}$. Subsequent addition of deionized water $(600 \mathrm{~mL})$ and $\mathrm{H}_{2} \mathrm{O}_{2}(30 \mathrm{v} \%, 30 \mathrm{~mL})$ results in the reduction of unreacted $\mathrm{KMnO}_{4}$. Wet graphite oxide with $\mathrm{pH}$ of about 7 was obtained by centrifugation, washing the paste with $\mathrm{HCl}$ solution $(10 \mathrm{v} \%)$, and washing the product three times with distilled water. Exfoliation of graphite oxide dispersion by a probe ultrasonic, filtration, and drying the product in vacuum at $65^{\circ} \mathrm{C}$ gives $\mathrm{GO}$.

\subsection{Preparation of furfuryl alcohol-functionalized GO (GOFA)}

Furfuryl alcohol was attached to the edge of GO by an esterification reaction. Accordingly, GO $(0.2 \mathrm{~g})$ and DMF $(120 \mathrm{~mL})$ were stirred in a flask for $24 \mathrm{~h}$ and then ultrasonically agitated for 30 min to reach a homogeneous dispersion. Subsequently, furfuryl alcohol $(0.47 \mathrm{~mL}, 5.41 \mathrm{mmol})$ was added into the flask and the dispersion was stirred for another $30 \mathrm{~min}$. Then, DCC (4.0 g, $20.87 \mathrm{mmol})$ and DMAP $(0.3 \mathrm{~g}, 2.46 \mathrm{mmol})$ were added slowly and the mixture was agitated for $16 \mathrm{~h}$. At the end, GOFA $(0.16 \mathrm{~g}, 80 \%)$ was obtained after filtration, washing the product with DMF for three times, and drying the solid in vacuum at $65^{\circ} \mathrm{C}$ for $24 \mathrm{~h}$ (Figure 1, Part I). 


\subsection{Preparation of (3-aminopropyl) triethoxysilane-functionalized GOFA (GOFASi)}

APTES was attached to the surface of GOFA by addition of amine moieties of APTES on the epoxy groups which frequently occur on GOFA surface [32]. Accordingly, GOFA (0.1 g) and ethanol $(50 \mathrm{~mL})$ were stirred in a flask for $24 \mathrm{~h}$ and then ultrasonically agitated for $30 \mathrm{~min}$ to reach a homogeneous mixture. Subsequently, after addition of DCC (0.1 g, $0.52 \mathrm{mmol})$, APTES in ethanol $(1.6$ in $10 \mathrm{~mL})$ was slowly added into the flask and stirring was continued at $70{ }^{\circ} \mathrm{C}$ for $20 \mathrm{~h}$. Then, the product was filtered through a $0.2 \mu \mathrm{m}$ PTFE filter and washed with ethanol for three times. After drying the product in oven at $65^{\circ} \mathrm{C}$, GOFASi was obtained $(0.072 \mathrm{~g}, 72 \%)$ (Figure 1, Part II).

\subsection{Preparation of graphene-containing silica aerogel (GA) and silica aerogel (SA)}

GA was prepared by an acid-catalyzed sol-gel process. GOFASi $(0.25 \mathrm{~g})$ and furfuryl alcohol $(8 \mathrm{~mL})$ were stirred in a flask for $24 \mathrm{~h}$ and then ultrasonically agitated for $30 \mathrm{~min}$ to reach a homogeneous mixture. Then, TEOS (1.25 g) and deionized water $(0.024 \mathrm{~g})$ were added to the flask. Subsequently, $\mathrm{HCl}$ was added in $0.03 \mathrm{wt} \%$ of the solution as the catalyst and stirring was continued for $1 \mathrm{~h}$. Then, GA was obtained by letting the mixture to remain at the room temperature for $12 \mathrm{~h}$ and $60{ }^{\circ} \mathrm{C}$ for $72 \mathrm{~h}$ (Figure 1, Part III). SA was also prepared by an acidcatalyzed sol-gel process similar to GA. Accordingly, TEOS (1.25 g) and deionized water (0.024 g) were added to a flask and after stirring for $30 \mathrm{~min}, \mathrm{HCl}$ was added in $0.03 \mathrm{wt} \%$ of the solution as the catalyst. For simplification of drying process, surface modification was carried out by immersion of the product in hexamethyldisilazane $(1.10 \mathrm{~mL})$ and $n$-hexane $(10 \mathrm{~mL})$ for $24 \mathrm{~h}$. SA was obtained after washing the product with $n$-hexane for three times and drying the product at $50{ }^{\circ} \mathrm{C}$ for $3 \mathrm{~h}, 150{ }^{\circ} \mathrm{C}$ for $2 \mathrm{~h}$, and $200{ }^{\circ} \mathrm{C}$ for $1 \mathrm{~h}$. 
2.6. Preparation of (3-glycidyloxypropyl) trimethoxysilane-modified novolac resin (MR)

Novolac resin modification was carried out by a ring opening reaction between epoxy groups of GPTS and hydroxyl groups of novolac resin, as reported previously [6]. Novolac resin (5 g) was dissolved in THF ( $5 \mathrm{~mL})$ in a flask. Subsequently, GPTES ( $2 \mathrm{~g})$ was added dropwise into the flask and the mixture left under stirring at $70{ }^{\circ} \mathrm{C}$ for $24 \mathrm{~h}$. The solution of modified resin was subsequently used in the preparation of GOFASi/MR composites (Figure 2, Part I).

\subsection{Preparation of GA/novolac composites (RGA)}

Calculated amounts of GA (50 and $25 \mathrm{mg}$ for 1 and $0.5 \mathrm{wt} \%$ respectively) and furfuryl alcohol $(5 \mathrm{~mL})$ were stirred in a flask for $24 \mathrm{~h}$ and then ultrasonically agitated for 30 min to reach a homogeneous mixture. Resin compounds were obtained by the addition of novolac resin solution ( $5 \mathrm{~g}$ resin in $5 \mathrm{~mL}$ furfuryl alcohol) and $0.7 \mathrm{~g}$ HMTA to the mixtures after agitation for $24 \mathrm{~h}$. The compounds are molded and cured as follows [6]: the mold temperature was increased to $80{ }^{\circ} \mathrm{C}$ by the rate of $2{ }^{\circ} \mathrm{C} / \mathrm{min}$ for drying the samples and remained in this state for $2 \mathrm{~h}$. Then, the mold temperature was held at $120{ }^{\circ} \mathrm{C}$ for $4 \mathrm{~h}$ and $180^{\circ} \mathrm{C}$ for $2 \mathrm{~h}$ for curing and $230{ }^{\circ} \mathrm{C}$ for $8 \mathrm{~h}$ for postcuring.

\subsection{Preparation of GOFASi/MR composites (MRGA)}

Calculated amounts of GOFASi (50 and $25 \mathrm{mg}$ for 1 and $0.5 \mathrm{wt} \%$ respectively) and furfuryl alcohol $(8 \mathrm{~mL})$ were stirred in a flask for $24 \mathrm{~h}$ and then ultrasonically agitated for $30 \mathrm{~min}$ to reach a homogeneous mixture. Modified novolac resin solution $(5 \mathrm{~g}$ modified resin in $5 \mathrm{~mL}$ THF) and HMTA $(0.7 \mathrm{~g})$ were added into the flask and agitated for $24 \mathrm{~h}$. In a beaker, TEOS $(1.25 \mathrm{~g})$ and deionized water $(0.024 \mathrm{~g})$ were agitated. $\mathrm{HCl}$ was added in $0.03 \mathrm{wt} \%$ of the solution as the catalyst and stirring was continued for $1 \mathrm{~h}$. The resin compounds were obtained by the addition of flask and beaker contents. The compounds were molded and cured as follows [6]: the 
mold temperature was increased to $80{ }^{\circ} \mathrm{C}$ by the rate of $2{ }^{\circ} \mathrm{C} / \mathrm{min}$ for drying the samples and remained in this state for $2 \mathrm{~h}$. Then, the mold temperature was held at $120{ }^{\circ} \mathrm{C}$ for $4 \mathrm{~h}$ and $180{ }^{\circ} \mathrm{C}$ for $2 \mathrm{~h}$ for curing and $230{ }^{\circ} \mathrm{C}$ for $8 \mathrm{~h}$ for post-curing (Figure 2, Part II).

\subsection{Characterization}

A Fourier transformed infrared (FTIR) spectrophotometer (Bruker, Germany) was used to collect the spectra at a $4 \mathrm{~cm}^{-1}$ resolution in the range of $500-4000 \mathrm{~cm}^{-1}$. An average of 32 scans for each sample was taken in a constant cell pathlength at room temperature. Samples were dispersed in $\mathrm{KBr}$ pellets and dried in vacuum desiccators.

Surface composition of the samples was analyzed by an X-ray photoelectron spectroscopy (XPS, Gammadata-Scienta Esca 200) equipped with an Al Ka (1486.6 eV photons) x-ray source in an ultra high vacuum at pass energies of 20 and $100 \mathrm{eV}$ for region and survey scan spectra.

Raman spectra were obtained in the range from 3500 to $100 \mathrm{~cm}^{-1}$ on a Senterra Dispersive Raman spectroscope (Bruker Optics, Germany) fitted with a $785 \mathrm{~nm}$ laser source, a CCD detector, and a confocal depth resolution of $2 \mu \mathrm{m}$. Laser power at the sample and spectral resolution was $50 \mathrm{~mW}$ and $3-5 \mathrm{~cm}^{-1}$ respectively. The laser beam was focused on the sample using an optical microscope.

Powder X-ray diffraction (XRD) spectra were recorded by a D5000 X-ray difractometer (Siemens, Germany) equipped with a scintillation counter and $\mathrm{Cu} K \alpha$ radiation $(\lambda=0.1540 \mathrm{~nm})$ at an accelerating voltage of $35 \mathrm{kV}$ and a current of $20 \mathrm{~mA}$. Samples were scanned from 2 to $40^{\circ}$ at the step scan mode. The basal spacing of the samples was calculated using the Bragg's equation $(\lambda=2 \mathrm{~d} \sin \theta)$.

Thermo gravimetric analysis (TGA) was carried out with a PL thermal analyzer (Polymer Laboratories, TGA 1000, Shropshire, UK) on a sample of about $10 \mathrm{mg}$. All TGA data were 
recorded from ambient temperature to $700{ }^{\circ} \mathrm{C}$ at a heating rate of $10{ }^{\circ} \mathrm{C} / \mathrm{min}$ and under $\mathrm{N}_{2}$ atmosphere at a flow rate of $50 \mathrm{~mL} / \mathrm{min}$.

Nitrogen gas adsorption and desorption measurements were carried out using a Micromeritics ASAP 2010 surface analyzer (Micromeritics Instrument Corporation, USA) at $76.09 \mathrm{~K}$. Adsorption-desorption isotherms, BET (Brunauer-Emmett-Teller) and Langmuir specific surface area, BJH (Barret-Joyner-Halenda) surface/volume mesopore analysis were obtained. Removal of any adsorbed species from the samples was carried out prior to the analysis at $250{ }^{\circ} \mathrm{C}$ and low vacuum for $12 \mathrm{~h}$.

Morphology of layers and aerogels was studied by scanning electron microscopy (Vega Tescan SEM instrument, Czech Republic). The specimens were prepared by precipitation of a thin sample layer on a mica surface using a spin coater (Modern Technology Development Institute, Iran) and its subsequent gold-coating using a sputtering coater.

The transmission electron microscope (Philips EM 208, Eindhoven, the Netherlands) with an accelerating voltage of $80 \mathrm{kV}$ was used to study the morphology of the layers and aerogels. Specimens were prepared by deposition of a thin sample layer on lacy grades from the ultrasonically agitated sample and ethanol dispersions. 


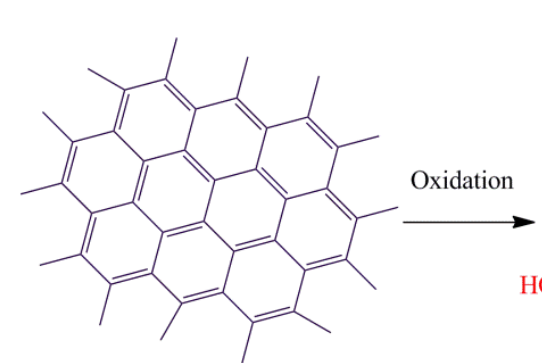

Graphite

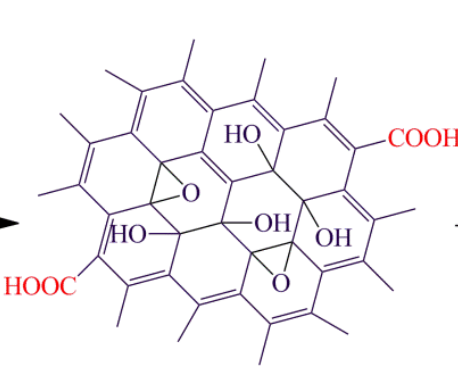

GO
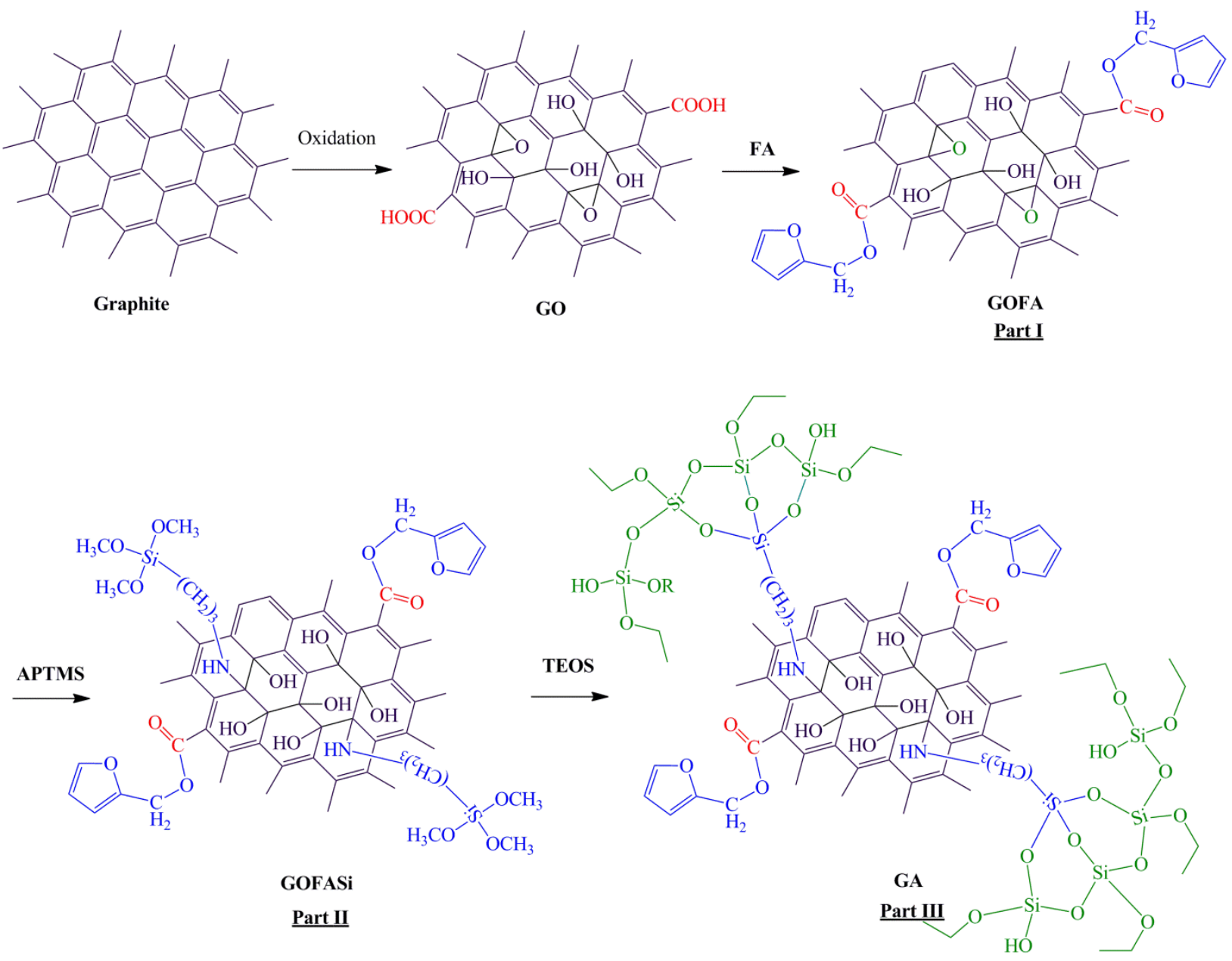

Figure 1- General scheme for synthesis of GO, GOFA, GOFASi, and GA 

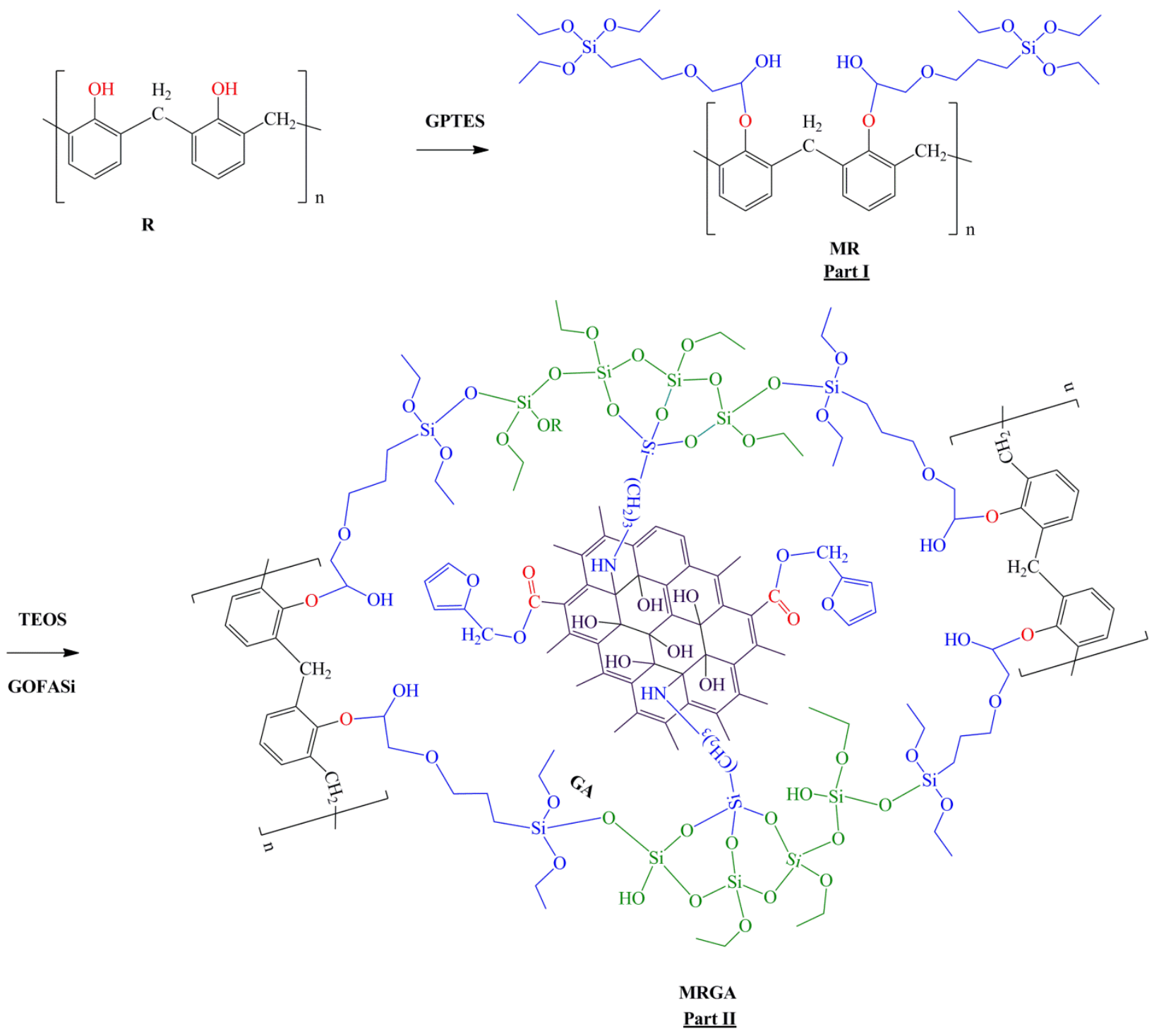

Figure 2- General scheme for modification of novolac resin and its incorporation into the silica and graphene network using GOFASi and TEOS

\section{Results and discussion}

Graphite was used to prepare GO by an oxidation reaction. As shown in Figure 1, furfuryl alcohol moieties were attached to the edge of GO by an esterification reaction to yield GOFA. Subsequently, APTES moieties were attached at the surface of GOFA by addition of amino groups on epoxy groups of GOFA, thus yielding GOFASi. Then, GA was obtained by 
incorporation of GOFASi into aerogel structure by using TEOS. GA at two different contents was used in novolac resin matrix to improve its carbon yield value and thermal properties. As shown in Figure 2, another procedure was used for thermal improvement of novolac resin. Accordingly, MR was obtained by structural modification of novolac resin by GPTES. Subsequently, MR, GOFASi, and TEOS were used as reactants in formation of graphenecontaining silica aerogel network. This finally results in incorporation of novolac resin and graphene layers into the silica/siloxane aerogel network.

FTIR spectra of G, GO, GOFA, GOFASi, and GA are shown in Figure 3 (A). Accordingly, GO adsorption spectrum shows some peaks at wave number of $1219 \mathrm{~cm}^{-1}(\mathrm{C}-\mathrm{OH}$ stretching vibration), $1722 \mathrm{~cm}^{-1}$ (C=O carboxyl stretching vibration), 1053 and $850 \mathrm{~cm}^{-1}$ (C-O vibration of epoxide groups), and $1623 \mathrm{~cm}^{-1}$ ( $\mathrm{C}=\mathrm{C}$ in aromatic ring) [33, 34]. The bands at 3412 and in the region of $2817-2972 \mathrm{~cm}^{-1}$ for GOFA, GOFASi, and GA are attributed to the stretching vibration of $\mathrm{O}-\mathrm{H}$ and $\mathrm{C}-\mathrm{H}$ respectively $[35,36]$. The bands at $743,1088,1208$, and $1554 \mathrm{~cm}^{-1}$ in the spectrum of GOFA are assigned to furan rings $[37,38]$. Out of the plane bending of $\mathrm{C}-\mathrm{H}$ and also $\mathrm{C}=\mathrm{C}$ linkages of furan rings are observed at 798 and $1650 \mathrm{~cm}^{-1}$ respectively. The bands at 1386 and $1727 \mathrm{~cm}^{-1}$ arise from aliphatic segments and from carbonyl groups, respectively [37]. The appearance of the intense band at $1093 \mathrm{~cm}^{-1}$ ( $\mathrm{Si}-\mathrm{O}$ stretching) is an evidence for successful attachment of APTES moieties to GOFA by a nucleophilic displacement reaction between epoxy groups of GO and amine moieties of APTES [9]. Additionally, the peak at $1568 \mathrm{~cm}^{-1}$ represents $\mathrm{N}-\mathrm{H}$ bending and $\mathrm{C}-\mathrm{N}$ stretching and confirms the successful ring opening reaction [39-42]. The shoulder at $1208 \mathrm{~cm}^{-1}$ for GOFASi and GA originates from $\mathrm{Si}-\mathrm{O}-\mathrm{CH}_{3}$ symmetric stretching. Also, $\mathrm{Si}-\mathrm{CH}_{2}$ asymmetric stretching is observed at $795 \mathrm{~cm}^{-1}$ for GOFASi and GA $[42,43]$. The 
band at $1622 \mathrm{~cm}^{-1}$ in the spectrum of GA also shows that $\mathrm{sp}^{2}$ carbon bonds are still remained in the aerogel structure.

Figure 3 (B) shows FTIR spectra for the neat, modified, and cured novolac resins, and also RGA1 and MRGA1. In all the resin-containing samples, the bands at 1092, 1500, about 1610 and in the 2793-2997 $\mathrm{cm}^{-1}$ region are assigned to asymmetric $\mathrm{C}-\mathrm{H}$ bending vibration of $\mathrm{CH}_{3}$ and $\mathrm{CH}_{2}$ groups, stretching vibration of $\mathrm{C}=\mathrm{C}$ bonds, $\mathrm{C}-\mathrm{O}$ vibration of phenol groups, and $\mathrm{C}-\mathrm{H}$ stretching vibration of $\mathrm{CH}_{3}$ and $\mathrm{CH}_{2}$ groups respectively [27, 44]. The bands at 757, 816, and $905 \mathrm{~cm}^{-1}$ show that the aromatic rings of $\mathrm{R}$ and MR contain a considerable amount of substituent groups [45]. After modification of R with GPTES, the shape of hydroxyl peak in $3000-3700 \mathrm{~cm}^{-}$ ${ }^{1}$ varies, since different hydroxyl group types are generated by the ring opening reaction [46]. Additionally, a peak at $1048 \mathrm{~cm}^{-1}$ is appeared, which is assigned to $\mathrm{Si}-\mathrm{OC}_{2} \mathrm{H}_{5}$ vibration of GPTES moieties. These observations clearly show that GPTES moieties are successfully attached to the backbone of $\mathrm{R}$. The vibration of $\mathrm{Si}-\mathrm{O}$ groups are also observed in RGA1 and MRGA1 spectra at $1010 \mathrm{~cm}^{-1}$, which confirms the presence of siloxane (or silica) networks in both of the samples. In addition, other characteristic peaks of $\mathrm{R}$ and MR with lower intensities can be observed in the spectra of RGA1 and MRGA1 respectively.
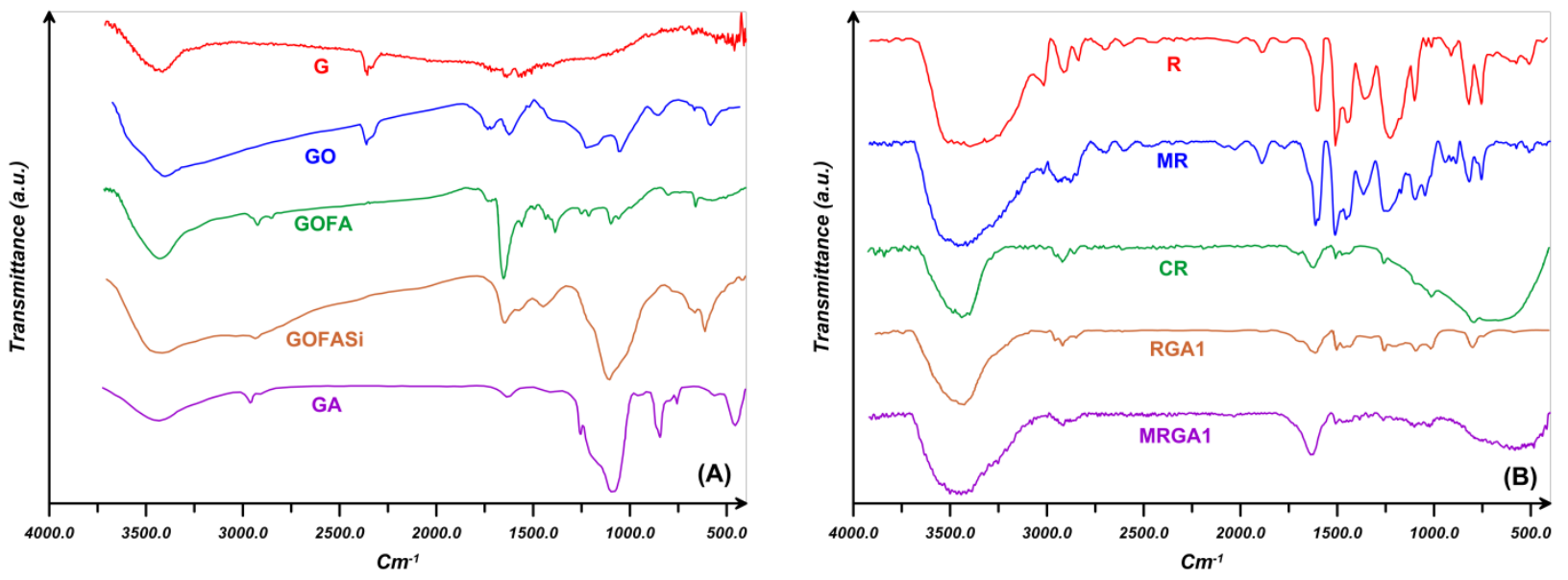
Figure 3- FTIR spectra for (A) G, GO, GOFA, GOFASi, and GA and also (B) R, MR, CR, RGA1, and MRGA1
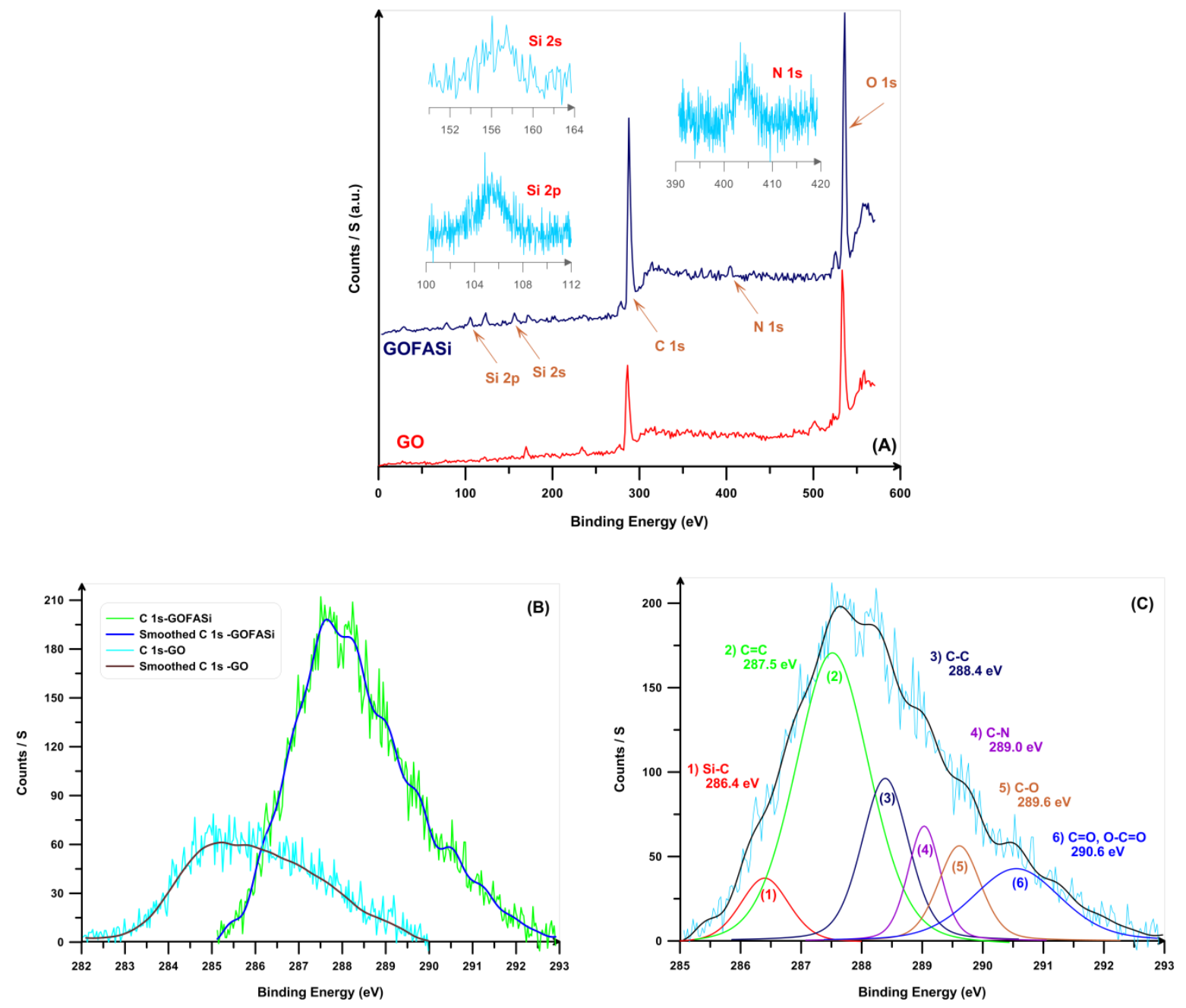

Figure 4- (A) Survey scan XPS spectra for GO and GOFASi, (B) C 1s core-level spectra for GO and GOFASi, and (C) deconvoluted C 1s core-level spectrum for GOFASi

As displayed in Figure 4, XPS was used to study the surface elemental composition of GO and GOFASi. Survey scan spectra for GO and GOFASi are displayed in Figure 4 (A). Additionally, N 1s, Si 2p, and Si 2s core-level spectra of GOFASi are presented in higher resolutions. It is clear that appearance of the bands for $\mathrm{N} 1 \mathrm{~s}$ at about 404.6, Si $2 \mathrm{p}$ at 105.5 , and $\mathrm{Si} 2 \mathrm{~s}$ at $157.1 \mathrm{eV}$ 
is a result of successful functionalization of GO with APTES moieties [9, 42, 47]. Partial reduction of GO can easily be observed by the increase of $\mathrm{C} 1 \mathrm{~s}$ peak area, as shown in Figure 4 (B). Besides the partial GO reduction during the modification, which was proven also by Raman spectroscopy (see below), the newly attached alkyl groups of APTES also likely contribute to the increased area of the C 1s peak. In figure $4(\mathrm{C}), \mathrm{C}$ 1s core-level spectrum is deconvoluted to some distinguished peak components. Appearance of $\mathrm{Si}-\mathrm{C}$ and $\mathrm{C}-\mathrm{N}$ peaks at 286.5 and $290.0 \mathrm{eV}$ clearly confirms the successful grafting of APTES moieties by the ring opening of epoxy functional groups [48, 49]. Table 2 summarizes the results of XPS as the amount of each functional group and atom content. Carbon to oxygen ratio is increased after functionalization of $\mathrm{GO}$, which is a result of partial reduction of GO layers. Carbon to silicon ratio of 15.48 from the survey scan spectrum of GOFASi shows that about 1 molecule of APTES was attached to every 2.5 aromatic rings of graphene. In addition, the reduction in the relative intensity of $\mathrm{C}-\mathrm{O}$ peak component and the increase in the relative intensities of $\mathrm{sp}^{2}$ and $\mathrm{sp}^{3}$ hybridized $\mathrm{C}-\mathrm{C}$ peak components are consistent with successful attachment of furfuryl alcohol and APTES moieties.

Table 2- Surface elemental composition of GO and GOFASi resulted from XPS (Data of GO is extracted from reference [50])

\begin{tabular}{|c|c|c|c|c|c|c|}
\hline \multirow{3}{*}{$\begin{array}{c}\text { Graphene } \\
\text { type }\end{array}$} & \multicolumn{6}{|c|}{ XPS data } \\
\hline & \multicolumn{4}{|c|}{ Composition (\%) } & \multicolumn{2}{|c|}{ Ratio } \\
\hline & $\mathrm{O}$ & $\mathrm{C}$ & $\mathrm{N}$ & $\mathrm{Si}$ & $\mathrm{C} / \mathrm{O}$ & $\mathrm{C} / \mathrm{Si}$ \\
\hline $\mathrm{GO}$ & 58.07 & 41.93 & ---- & $\begin{array}{l}--- \\
\end{array}$ & 0.72 & ---- \\
\hline \multirow[t]{2}{*}{ GOFASi } & 28.40 & 63.62 & 3.87 & 4.11 & 2.24 & 15.48 \\
\hline & \multicolumn{6}{|c|}{ Composition of $\mathrm{C}$ in groups } \\
\hline
\end{tabular}




\begin{tabular}{|c|c|c|c|c|c|c|}
\hline & $\begin{array}{c}\mathrm{O}=\mathrm{C}-\mathrm{O}, \\
\mathrm{C}=\mathrm{O}\end{array}$ & $\mathrm{C}-\mathrm{O}$ & $\mathrm{C}-\mathrm{C}$ & $\mathrm{C}=\mathrm{C}$ & $\mathrm{C}-\mathrm{N}$ & $\mathrm{Si}-\mathrm{C}$ \\
\hline GO & 36.19 & 33.89 & 8.69 & 21.23 & ---- & ---- \\
\hline GOFASi & 13.61 & 9.62 & 16.31 & 45.28 & 8.99 & 6.19 \\
\hline
\end{tabular}

Raman spectroscopy is highly sensitive to electronic structure in double bond-containing carbon materials. Thus, it was used to study the ordered and disordered carbon crystal structures in G, GO, GOFA, GOFASi, and GA (Figure 5). According to the results, three characteristic peaks of G can be observed. Diamond (D) band at $1311 \mathrm{~cm}^{-1}$ comes from the breathing mode of $\kappa$-point phonons of $\mathrm{A}_{1 \mathrm{~g}}$ symmetry and is assigned to the defects ( $\mathrm{sp}^{3}$ carbon) and also to the edge effect of graphene platelets. Graphitic (G) band at $1578 \mathrm{~cm}^{-1}$ originates from the first order scattering of the $\mathrm{E}_{2 \mathrm{~g}}$ phonons of $\mathrm{sp}^{2}$-carbon atoms and is attributed to the ordered aromatic domains. 2D band at $2640 \mathrm{~cm}^{-1}$ is related to the stacking order of carbon layers and commonly used for determination of graphene layers number [33-35, 51]. The shape of 2D band and its position are important factor in distinguishing between the single layer, bilayer, and multilayer graphenes. Single layer graphene shows a single 2D peak below $2700 \mathrm{~cm}^{-1}$; however, bilayer graphene diplays a broader up-shifted 2D peak near $2700 \mathrm{~cm}^{-1}$. The 2D peak for multilayer graphene appeared at higher than $2700 \mathrm{~cm}^{-1}$ [52]. By oxidation of G, D and G bands are appeared at 1299 and $1595 \mathrm{~cm}^{-1}$ respectively. In addition, the intensity ratio of $\mathrm{D}$ to $\mathrm{G}$ bands $\left(\mathrm{I}_{\mathrm{D}} / \mathrm{I}_{\mathrm{G}}\right)$ increases considerably (from 0.58 for $\mathrm{G}$ to 1.45 for $\mathrm{GO}$ ), which indicates the decrease of graphitic network size upon the oxidation process [53]. $\mathrm{I}_{\mathrm{D}} / \mathrm{I}_{\mathrm{G}}$ values for GOFA and GOFASi (1.19 and 1.03 respectively) show that GO layers are partially reduced upon the functionalization processes. Partial reduction of GO by functionalization was also reported previously [33, 54]. In addition, the lower $I_{D} / I_{G}$ ratio for GOFASi compared with GOFA indicates that the graphitic crystallite 
size is higher in GOFASi. Also, 2D peak disappeared by the oxidation and functionalization of graphene with furfuryl alcohol and APTES moieties. This clearly shows that stacking order is reduced and layers are exfoliated [34, 53]. GOFASi shows a small peak at $512 \mathrm{~cm}^{-1}$ which corresponds to the presence of silicon $[55,56]$. Interestingly, GA shows a very different spectrum compared with the others. Disappearance of $2 \mathrm{D}$ and $\mathrm{G}$ bands, severe decrease of $\mathrm{D}$ band intensity, and also appearance of some peaks at below $1000 \mathrm{~cm}^{-1}$ show that layered structure of graphene is destroyed and can be an evidence for aerogel formation. Sever decrease of $\mathrm{D}$ and $\mathrm{G}$ band intensities upon the formation of aerogel was also reported by Zhang et al., who prepared aerogels by hydrothermal method [57]. Very high value of $\mathrm{I}_{\mathrm{D}} / \mathrm{I}_{\mathrm{G}}$ for $\mathrm{GA}$ shows that the size of continuos areas of $\mathrm{sp}^{2}$ carbon is very small while $\mathrm{sp}^{3}$ carbon is dominant, which is also resulted from the aerogel network formation. Additionally, the peaks at 545 and $1060 \mathrm{~cm}^{-1}$ are attributed to $\mathrm{Si}-\mathrm{O}$ network $[55,58]$ and the peaks at 742 and $946 \mathrm{~cm}^{-1}$ are assigned to $\mathrm{Si}-\mathrm{C}$ group $[59,60]$.

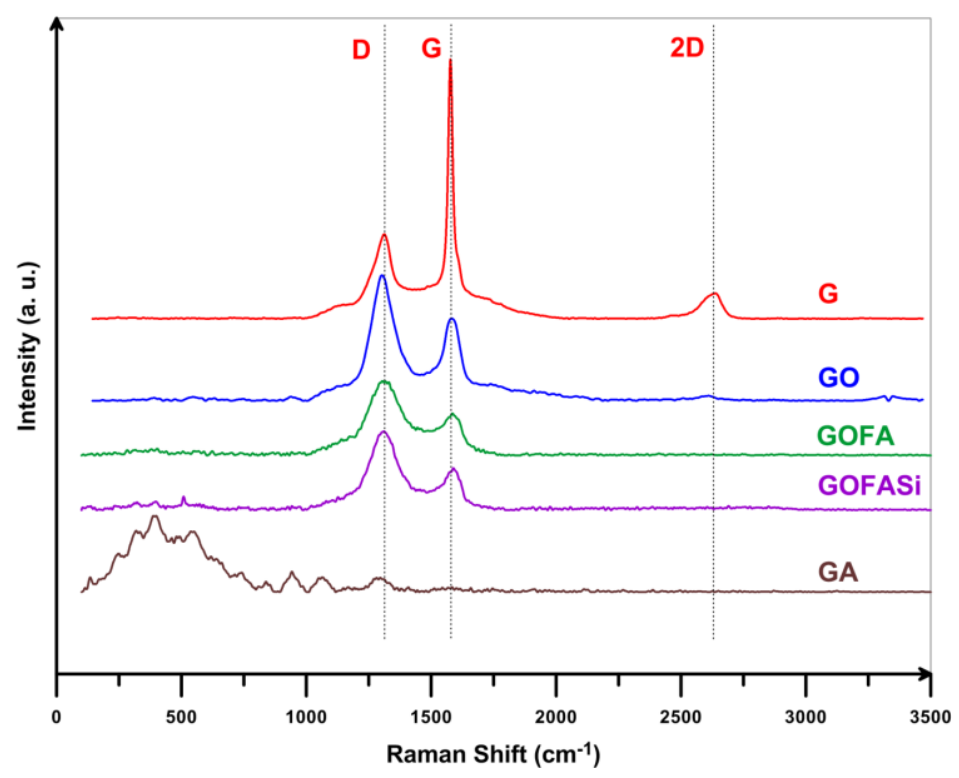

Figure 5- Raman spectra for G, GO, GOFA, GOFASi, and GA 
Evaluation of graphene structure and its interlayer expansion upon the oxidation, modification, and aerogel formation processes was carried out using XRD patterns. The XRD patterns for G, GO, GOFA, GOFASi, GA, R, RGA0.5, and MRGA0.5 are displayed in Figure 6. Results show that oxidation of graphene layers expands their interlayer spacing from 0.34 to $0.93 \mathrm{~nm}$ (variation of diffraction angle from 26 to $9.52^{\circ}$ ) as a result of formation of oxygen-containing functional groups. Additionally, decrease of $\mathrm{sp}^{2}$-hybridized crystalline domains size and therefore looser stacking of layers upon the oxidation results in broadening of XRD peak, which justifies the Raman results [61]. Attachment of furfuryl alcohol moieties to the edge of GO further expands the interlayer spacing to the value of $1.10 \mathrm{~nm}$ (diffraction angle of $8^{\circ}$ ). Ring opening reaction of GOFA epoxy groups by APTES amine moieties results in further increase of the interlayer spacing to the value of $1.64 \mathrm{~nm}\left(5.37^{\circ}\right)$. As described, there is not any peak related to GO in the diffraction pattern of GOFA and GOFASi, which clearly shows that layers are disordered during the modification processes [62]. The peak at $30.12^{\circ}$ originates from APTES moieties [47]. GA shows a broad peak at diffraction angle of $21.16^{\circ}$ which corresponds to the (002) reflection of the graphene layers and indicating the poor ordering of layers along their stacking direction [63, 64]. The interlayer spacing of GA is calculated to be $0.41 \mathrm{~nm}$. These results confirm $\pi-\pi$ stacking in aerogels [65]. It originates from the coherent diffraction of $\mathrm{Si}-\mathrm{O}$ based domains and is an evidence for the formation of aerogel structure [66, 67]. It is also observed that no characteristic peak of GO or modified GOs is observed in the diffraction pattern of GA, which is an indication of a good dispersion of layers in the aerogel matrix without any overlap $[68,69]$. Additionally, the broad peak of GA strongly confirms the formation of aerogel structure [70]. In the case of $\mathrm{R}$, the amorphous peak at around $19.5^{\circ}$ is characteristic of phenolic resins [71]. According to the fact that there is not any peak other than GA and the amorphous $R$ 
peak in the XRD patterns of RGA0.5 and MRGA0.5, it can be concluded that there is not any stacked form of graphene layers in the GA/novolac and GOFASi/modified novolac hybrids different from GA stacking.

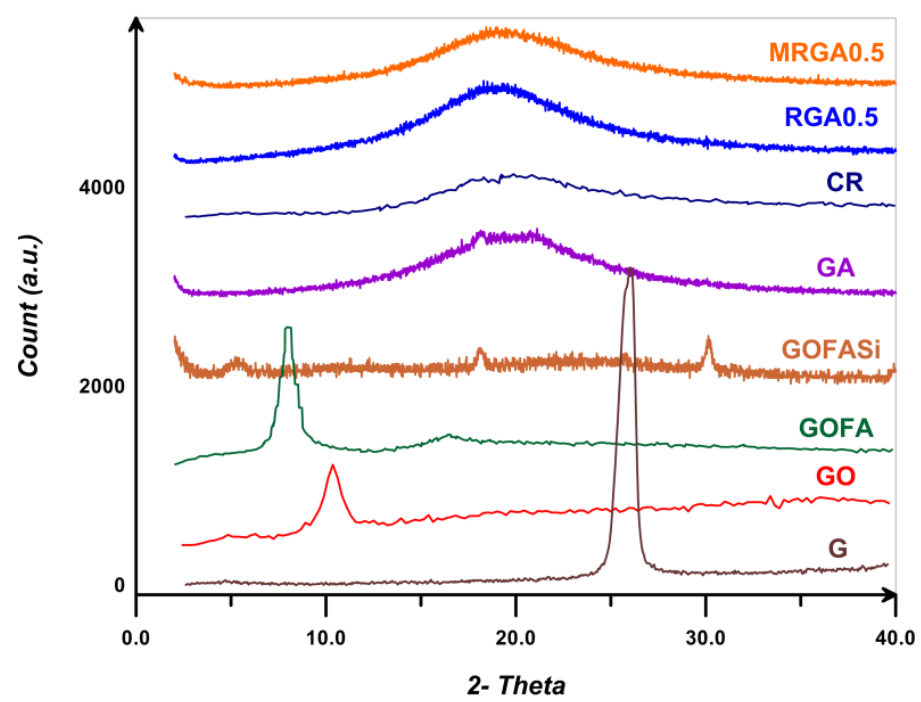

Figure 6- XRD patterns for G, GO, GOFA, GOFASi, GA, CR, RGA0.5, and MRGA0.5
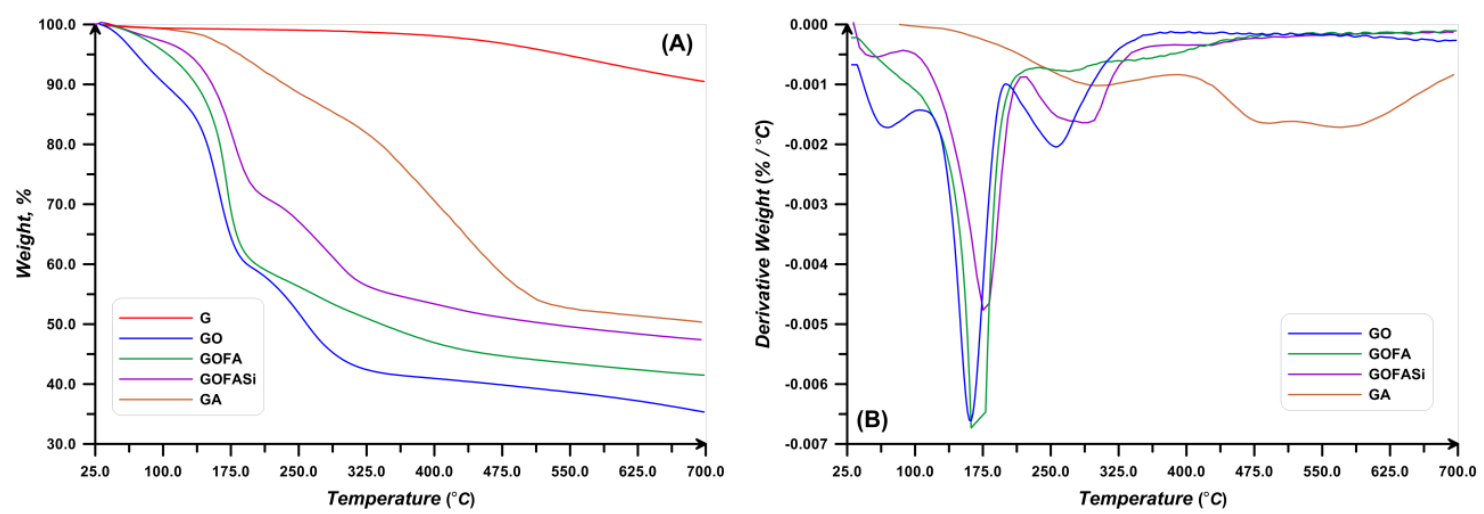

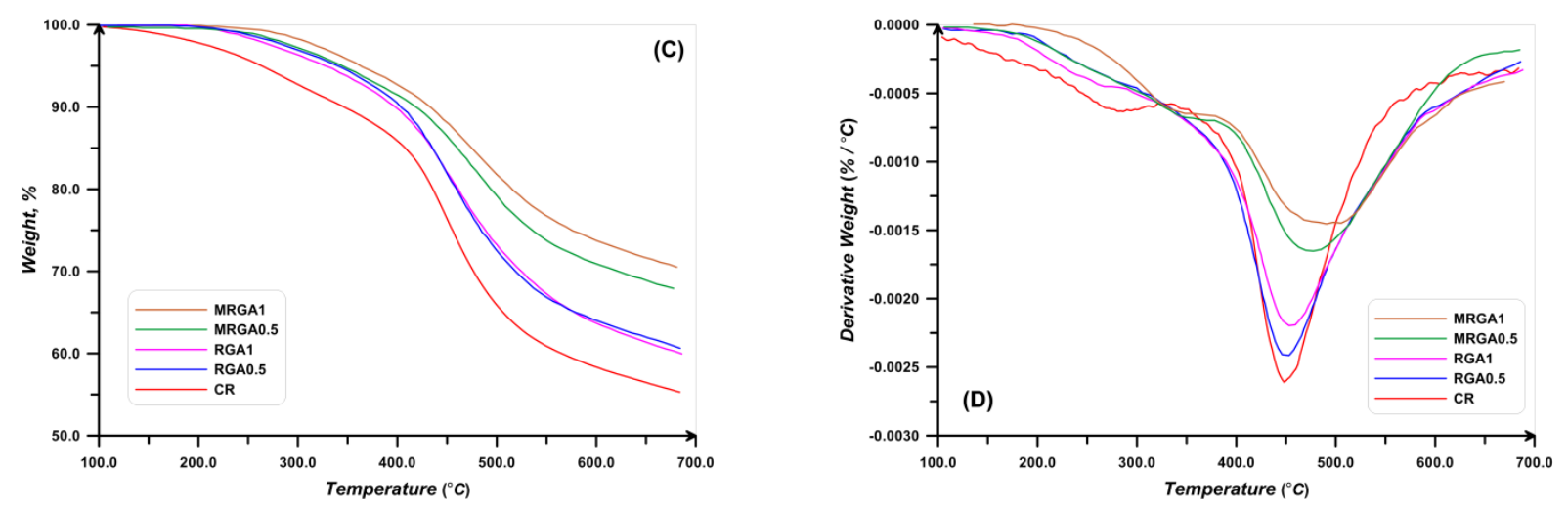

Figure 7- (A) TGA and (B) DTG curves of G, modified graphenes, and GA and also (C) TGA and (D) DTG curves of CR and its composites

Thermogravimetric analysis of various graphenes, novolac resin, and its composites is carried out in $\mathrm{N}_{2}$ atmosphere and the results are displayed in Figure 7 and Table 3. According to the results of Figure 7 (A) and (B), G is almost stable till $700{ }^{\circ} \mathrm{C}$ with char value of about $93.2 \%$. However, GO is unstable and losses mass upon heating in three stages. The first decomposition step occurs at below $100{ }^{\circ} \mathrm{C}$ and originates from absorbed water in its $\pi$-stacked structure [72, 73]. The second step, between 150 and $220{ }^{\circ} \mathrm{C}$, is attributed to release of $\mathrm{CO}$ and $\mathrm{CO}_{2}$ from the most labile oxygen-containing functional groups. The third step, between 200 and $350{ }^{\circ} \mathrm{C}$, is assigned to the degradation of more stable oxygen functionalities [74]. Finally, GO reaches to char value of about $35.3 \%$ at $700{ }^{\circ} \mathrm{C}$. Successful functionalization of GO with furfuryl alchohol and APTES moieties from the edge carboxyl groups and surface epoxies is also reflected by TGA curves. The content of oxygen functional groups is reduced during the edge and surface functionalization processes; therefore, a different decomposition patterns are observed for GOFA and GOFASi. The char value of about $41.5 \%$ for $\mathrm{GOFA}$ at $700{ }^{\circ} \mathrm{C}$ is related to the decomposition of furfuryl alcohol and remained oxygen functionalities. GOFASi thermogram reaches to $47.3 \%$ at $700{ }^{\circ} \mathrm{C}$ as a result of degradation of APTES moieties in addition to furfuryl alcohol and remained oxygen functionalities. Decrease of weight loss at the second and third 
steps for GOFA and GOFASi with respect to GO arises from the decrease of the content of oxygen-containing functional groups and confirms the successful functionalization processes $[33,34]$. This is also confirmed by the reduction of weight loss at the first step by further functionalization of GO by furfuryl alcohol and APTES moieties as a result of lower water adsorption. The differences between the char yields of GOFA and GOFASi with GO can be a rough estimation of modifier content. Consequently, weight ratio of furfuryl alcohol in GOFA and APTES in GOFASi is estimated to be 6.2 and 5.8\% respectively. Interestingly, weight loss and its derivative thermograms for GA are different from the others. This mainly originates from the presence of $\mathrm{Si}-\mathrm{O}$ groups and network formation. The weight loss below $100{ }^{\circ} \mathrm{C}$ is very low for GA, which shows very low amount of water adsorption as a result of removal of thermally labile oxygen functionalities after two modification processes and a silane network formation. Figure 7 (B) shows that GA decomposition occurs at two steps. The weight loss of about $17.3 \%$ at about $305{ }^{\circ} \mathrm{C}$ can be assigned to the decomposition of remained oxygen functionalities. The low weight loss at this step shows that most of oxygen functional groups have been converted during the reactions with furfuryl alcohol and APTES and also silane network formation. The second step with a weight loss of $30.6 \%$ can be assigned to the pyrolysis of silane moieties and carbon skeleton $[9,67]$ at two stages (respectively at about 480 and $575^{\circ} \mathrm{C}$ ). DTG peak of GA shows that the second degradation step mainly occurs by the decomposition of carbon skeleton. This proves that graphene layers are the dominant component in GA and that siloxane moieties or silica from TEOS act as agents supporting aerogel formation. From the char value of about $50.4 \%$ for GA, one can estimate that about $3.1 \mathrm{wt} \%$ of GA is composed of silane moieties. Figure 7 (B) and Table 3 shows that the decomposition temperatures of GO is lower than GOFA and GOFASi as a result of its higher content of oxygen-containing functional groups. The weight 
and molar ratio of furfuryl alcohol and APTES moieties in the graphene layers can be calculated from TGA thermograms using Equations 1-2 [35, 75-76].

$G_{r, M}($ weight ratio of modifier on graphene $)=\frac{w \%_{M}}{100-w \%_{M}}$

$G_{p, M}($ molar ratio of modifier on graphene $)=\frac{\left(\frac{w \%_{M}}{100-w \%_{M}}\right)}{M_{M}}$

where, $\mathrm{w}_{\mathrm{M}}$ and $\mathrm{M}_{\mathrm{M}}$ denote the weight loss and molecular weights for the modifier respectively. In the case of GOFA, considering modifier content of $6.2 \mathrm{wt} \%$ and furfuryl alcohol molecular weight of about 97.10 g. $\mathrm{mol}^{-1}, \mathrm{G}_{\mathrm{r}, \mathrm{FA}}$ and $\mathrm{G}_{\mathrm{p}, \mathrm{FA}}$ are calculated to be $6.61 \times 10^{-2}$ and $680.7 \mu \mathrm{mol} / \mathrm{g}$ respectively. Regarding GOFASi, APTES content of $5.8 \mathrm{wt} \%$ and its molecular weight of about 221.37 g.mol ${ }^{-1}$ results in $G_{r, A P T E S}$ and $G_{p, A P T E S}$ values of $6.15 \times 10^{-2}$ and $278.1 \mu \mathrm{mol} / \mathrm{g}$ respectively.

In accord with the results of Figure 7 (C) and (D), char value for the novolac resin is about $55.3 \%$. By the addition of $0.5 \mathrm{wt} \%$ of GA, this value is increased to $60.7 \%$. However, the synthesis of the hybrid novolac by molecularly blending and condensing modified resin with GOFASi and TEOS results in a much higher char value of $70.6 \%$ in the presence of $1 \mathrm{wt} \%$ of GOFASi. This clearly shows that in addition to the increase of char value by the addition of GA content, structural modification of novolac resin and its incorporation into the aerogel network can increase the char value significantly. Char value of $70.6 \%$ at $700{ }^{\circ} \mathrm{C}$ confirms the structural stability at higher temperatures. Our previous work on novolac composites with GO and GOFA showed that char value increases to 60.6 and $62.1 \%$ by the addition of GO and GOFA respectively [27]. This confirms that functionalization of GO with furfuryl alcohol moieties makes it more compatible with the novolac and furfuryl alcohol mixture before curing. Also, 
GOFA is involved in the curing reaction via its furfuryl alcohol moieties and results in higher char values. Interestingly, char value increases considerably in the case of MRGA samples. Higher compatibility of furfuryl alcohol-modified graphene layers with novolac resin mixture, incorporation of GPTES-modified novolac resin in the silane network of GOFASi and TEOS, and subsequent curing of novolac resin result in a cured hybrid of graphene, novolac resin, and silane network with such an improved thermal properties. This new material is further compared with the other novolac resins with improved thermal properties in Table 4. Additionally, thermal stabilities of the entire composites are higher than the neat novolac resin. DTG peak point, as an indication of degradation temperature, increases by the addition of GA content. Noticeably, resin modification and its incorporation into the aerogel network increases thermal stability of novolac resin. Finally, degradation temperature of novolac resin increased from 448 to $496{ }^{\circ} \mathrm{C}$ by the addition of only $1 \mathrm{wt} \%$ GOFASi, modification of resin, and hybrid aerogel formation.

Table 3- Summary of TGA results

\begin{tabular}{|c|c|c|c|c|c|}
\hline Sample & DTG peak point $\left({ }^{\circ} \mathrm{C}\right)$ & Char $(\%)$ & Sample & DTG peak point $\left({ }^{\circ} \mathrm{C}\right)$ & Char $(\%)$ \\
\hline G & --- & 93.2 & $\mathrm{R}$ & 448 & 55.3 \\
\hline GO & 69,161, and 257 & 35.3 & RGA05 & 451 & 60.7 \\
\hline GOFA & 171,266 & 41.5 & RGA1 & 455 & 60.1 \\
\hline GOFASi & 179,279 & 47.3 & MRGA05 & 475 & 67.9 \\
\hline GA & 301,485 , and 579 & 50.4 & MRGA1 & 492 & 70.6 \\
\hline
\end{tabular}

Table 4 shows increase of carbon yield value in thermally-reinforced novolac resins with three methods of conventional chemical additives, nanofiller addition, and combination of chemical 
additives and nanofiller addition. It can be seen that the chemical additives method requires a considerable additive content compared with the nanofiller method. Commonly, boron- and phosphorous-containing chemicals were used in chemical additives method to improve the thermal properties and most importantly carbon yield value. In the case of boron-containing chemical additives, mixture of boric acid terminated hyperbranched polyborate (HBp) and phenolic resin was prepared by Liu and Jing [20]. They showed that char value is increased from 64.2 to $75.4 \%$ for the neat and modified phenolic resins respectively. Xu and Jing used HBp as an additive and reached carbon yield value of 71.3 and $73.1 \%$ by the addition of 10 and $20 \mathrm{wt} \%$ of HBp [21]. They also reported variation of char value from $63.8 \%$ to $71.3,62.1$, and $78.4 \%$ by the addition of 10, 50, and $80 \mathrm{wt} \%$ of HBp [22]. Wang et al. reported an aryl-boron-containing phenolic resin prepared by reacting phenylboronic acid with phenolic resin [23]. They showed that $10 \mathrm{wt} \%$ of phenylboronic acid addition resulted in carbon yield value of $76.4 \%$ at $800{ }^{\circ} \mathrm{C}$, which is much higher than phenolic resin char value of $63.0 \%$. In a similar work, they also showed that an aryl-boron-containing phenolic resin synthesized from phenol, formaldehyde, and phenylboronic acid has carbon yield value of $70.0 \%$ at $1000{ }^{\circ} \mathrm{C}$, which is also higher than phenolic resin char value of $60.0 \%$ [77]. Considering phosphorous-containing phenolic resins, Hsiue et al. improved the char value of a selected phenolic resin by $35 \%$ with the addition of only 7.79 wt\% of diethylphosphoryl chloride. However, low char value of unmodified resin results in a low carbon yield value for these materials at $700{ }^{\circ} \mathrm{C}$ [24]. On the other hand, a very low content of carbon nanofillers results in high carbon yield values. In our previous work, we reached to the carbon yield value of about 60.55 and $62.09 \%$ by the addition of only $0.4 \mathrm{wt} \%$ of GO and GOFA respectively [27]. We concluded that modification of GO with furfuryl alcohol improved the final char value to some extent, because of involving garphene layers in the curing 
reaction via its furfuryl alcohol moieties. Similar results were obtained by Zhao et al. in the in situ synthesis of reduced GO/phenol formaldehyde composites [28]. Phenol adsorption on the surface of reduced GO via noncovalent $\pi-\pi$ stacking and its subsequent participation in the polymerization result in the arrangement of resin chains on the reduced GO surface. They reached to the char value of $63.25 \%$ by the addition of $1 \mathrm{wt} \%$ of reduced GO. Cui et al. used MWCNT and carboxylated MWCNT in the in situ polymerization of phenol formaldehyde and observed 59.6, 60.1, and 62.7\% carbon yield values for the neat, MWCNT-, and carboxylated MWCNT-loaded phenol formaldehydes respectively [29]. Considering additive and nanofiller methods, an improvement of thermal properties of a boron-containing phenolic resin was carried out by Liu and Ye [30] and 5.2\% increase of carbon yield value was achieved by addition of only $1 \mathrm{wt} \%$ of MWCNT. We showed that addition of only $0.4 \mathrm{wt} \%$ of GOFA results in $6.8 \%$ increase of char value of novolac resin [27]. In the current work, we studied the effect of GA addition and also resin incorporation in graphene-containing silica aerogel network on char value of novolac resin and we increased the char value by $4.4 \%$. To increase this value, in addition to furfuryl alcohol and APTES functionalization of graphene layers, phenolic resin incorporation into the graphene-containing silica aerogel network was accomplished by silane modification of resin. Interestingly, $15.3 \%$ increase for char value was observed by the network formation. We think that the final carbon yield value of this resin network can be increased by using resins with higher char values or using structural modified resins with boron- or phosphorous-containing materials. It is an ongoing work in our group to use a structural-modified phenolic resin with boron and silane moieties to form aerogel with furfuryl alcohol- and silane-modified graphene for more increase of final carbon yield value. We guess to reach a higher carbon yield values compared with MRGA1. 
Table 4- Increase of carbon yield values in various structural modification of novolac resins and nanofiller addition

\begin{tabular}{|c|c|c|c|c|c|c|}
\hline \multicolumn{2}{|r|}{ Method } & Resin Char ${ }^{1}$ & Final Char & Additive Content & Increase & Ref \\
\hline \multirow{10}{*}{ Additives } & Boron-containing chemical & 64.2 & 75.4 & 10 & 11.2 & [20] \\
\hline & Boron-containing chemical & 63.8 & 71.3 & 10 & 7.5 & [21] \\
\hline & Boron-containing chemical & 63.8 & 73.1 & 20 & 9.3 & {$[21]$} \\
\hline & Boron-containing chemical & 63.8 & 71.3 & 10 & 7.5 & [22] \\
\hline & Boron-containing chemical & 63.8 & 62.1 & 50 & -1.7 & {$[22]$} \\
\hline & Boron-containing chemical & 63.8 & 78.4 & 80 & 14.6 & {$[22]$} \\
\hline & Boron structural modification & 63.0 & 76.4 & 10 & 13.4 & [23] \\
\hline & Phosphorus modification & 12 & 39 & 3.46 & 27 & [24] \\
\hline & Phosphorus modification & 12 & 43 & 5.50 & 31 & [24] \\
\hline & Phosphorus modification & 12 & 47 & 7.79 & 35 & [24] \\
\hline \multirow{3}{*}{ Nano } & GO-containing & 55.29 & 60.55 & 0.4 & 5.26 & [27] \\
\hline & GOFA-containing & 55.29 & 62.09 & 0.4 & 6.8 & [27] \\
\hline & Reduced GO-containing & 55.25 & 63.25 & 1 & 8.0 & [28] \\
\hline
\end{tabular}




\begin{tabular}{|c|c|c|c|c|c|c|}
\hline & Carboxylated MWCNT & 59.6 & 62.7 & 0.95 & 3.1 & [29] \\
\hline & GA-containing & 55.3 & 60.7 & 0.5 & 5.4 & This Work \\
\hline & GA-containing & 55.3 & 60.1 & 1 & 4.7 & This Work \\
\hline \multirow{3}{*}{$\begin{array}{l}\text { Additives } \\
\text { \& Nano }\end{array}$} & MWCNT and Boron modification & $66^{2}$ & 68.7 & 0.25 & 2.7 & [30] \\
\hline & MWCNT and Boron modification & $66^{2}$ & 70.9 & 0.5 & 4.9 & {$[30]$} \\
\hline & MWCNT and Boron modification & $66^{2}$ & 72.2 & 1 & 5.2 & [30] \\
\hline \multirow{2}{*}{ Sol-gel } & Novolac resin/GOFASi hybrid & 55.3 & 67.9 & 0.5 & 12.6 & This Work \\
\hline & Novolac resin/GOFASi hybrid & 55.3 & 70.6 & 1 & 15.3 & This Work \\
\hline
\end{tabular}

1 heating rate of $10{ }^{\circ} \mathrm{C} / \mathrm{min}$ except for MWCNT/Boron modification with $20^{\circ} \mathrm{C} / \mathrm{min}$

2 for boron-containing resin 

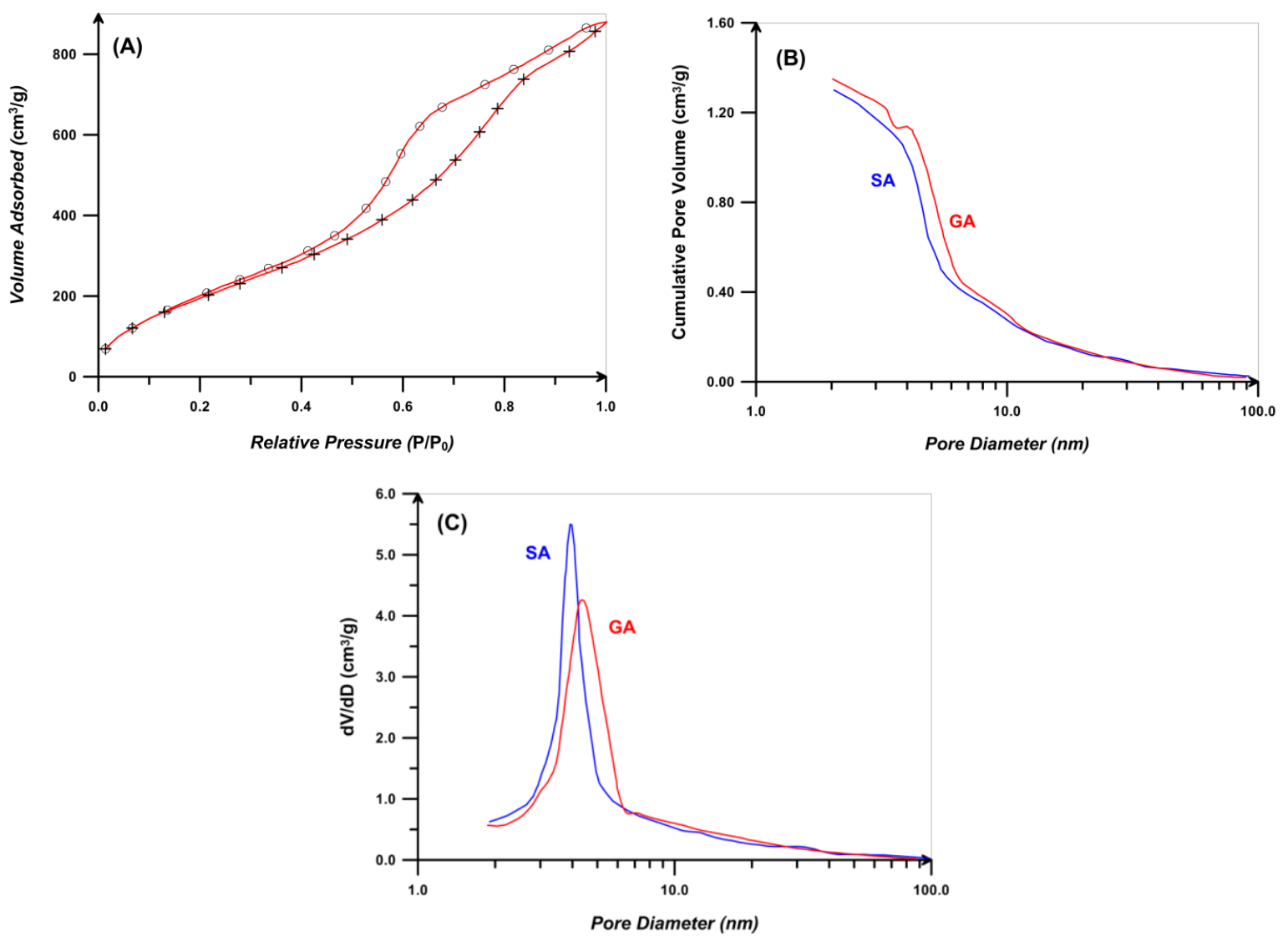

Figure 8- (A) Nitrogen adsorption-desorption isotherm for GA, (B) BJH desorption cumulative pore volume of SA and GA, and (C) pore size distribution curves of SA and GA

As shown in Figure 8 (A), microstructural feature of GA is investigated by multilayer nitrogen adsorption-desorption isotherms at 76.11 K (Brunauer-Emmett-Teller (BET) technique [78]). The isotherm is type IV with a pronounced type H3 hysteresis loop attributed to the capillary condensation and suggesting mesoporous structures [70, 79]. According to IUPAC, mesopores are pores with diameters between 2 and $50 \mathrm{~nm}$. Pores with diameters less than $2 \mathrm{~nm}$ are named micropores and macropores is ascribed to pores of diameters larger than $50 \mathrm{~nm}$ [17]. The rapid increase of gas adsorption at low relative pressures $\left(\mathrm{P} / \mathrm{P}_{0}<0.01\right)$ is attributed to micropores $[16$, 17]. This shows that GA contains a little amount of micropores. Cumulative pore volume plot and also pore size distribution curve, $\mathrm{dV} / \mathrm{dD}$ as a function of $\mathrm{D}$, are obtained from the Barret- 
Joyner-Halenda (BJH) method using nitrogen adsorption-desorption data [80] and the curves for SA and GA are shown in Figure 8 (B and C). Interestingly, incorporation of graphene layers into the aerogel network results in higher cumulative pore volume values and also broader pore diameter distribution curve with a larger peak point value. This means that pores are increased in diameter and they become more heterogeneous in size in the presence of graphene layers. The pore size of SA and GA ranges from 2 to about $100 \mathrm{~nm}$; however, size of a large number of pores is between 2 and $10 \mathrm{~nm}$ in both of them. This shows that SA and GA can be included in the mesoporous materials category. Higher pore size of GA may result from the heaping of graphene layers [70]. Considering cylindrical pore geometry, pore diameter of a material can be estimated form the volume of the gas required to fill all the pores as $\mathrm{D}=4 \mathrm{~V}_{\mathrm{p}} / \mathrm{S}_{\mathrm{BET}}$, where $\mathrm{D}$ is the average pore diameter and $\mathrm{V}_{\mathrm{p}}$ is the pore volume [81]. BET surface area $\left(\mathrm{S}_{\mathrm{BET}}\right)$ for SA and GA is calculated from the linear plot of $1 /\left[\mathrm{V}_{\mathrm{A}} \times\left(\mathrm{P}_{0} / \mathrm{P}\right)-1\right]$ against relative pressure $\left(\mathrm{P}_{0} / \mathrm{P}\right)$ (SI: Figure 1 (A)), where $\mathrm{V}_{\mathrm{A}}$ is assigned to the volume of adsorbed gas [78, 81]. Additionally, Langmuir surface area ( $\left.\mathrm{S}_{\text {Langmuir }}\right)$ for $\mathrm{SA}$ and $\mathrm{GA}$ is obtained from the linear plot of $1 /\left[\mathrm{V}_{\mathrm{A}} \times\left(\mathrm{P}_{0} / \mathrm{P}\right)\right]$ against relative pressure $\left(\mathrm{P}_{0} / \mathrm{P}\right)$ (SI: Figure $\left.1(\mathrm{~B})\right)$ [82]. Specific surface area by BET, Langmuir, and BJH methods, pore volumes, and pore diameters are calculated from the BET, Langmuir, and BJH plots and the results are presented in Table 5. Accordingly, the average pore sizes of 5.90 and 6.58 respectively for SA and GA show their mesoporous structure. High surface area and suitable pore size are characteristics of both SA and GA products.

Table 5- Detailed results of nitrogen adsorption-desorption isotherms for SA and GA

\begin{tabular}{|c|c|c|c|c|c|c|}
\hline Sample & $\begin{array}{c}\mathrm{S}_{\mathrm{BET}} \\
\left(\mathrm{m}^{2} \mathrm{~g}^{-1}\right)\end{array}$ & $\begin{array}{c}\mathrm{S}_{\text {Langmuir }} \\
\left(\mathrm{m}^{2} \mathrm{~g}^{-1}\right)\end{array}$ & $\begin{array}{c}\mathrm{S}_{\mathrm{BJH}}{ }^{1} \\
\left(\mathrm{~m}^{2} \mathrm{~g}^{-1}\right)\end{array}$ & $\begin{array}{c}\mathrm{V}_{\mathrm{BJH}}{ }^{2} \\
\left(\mathrm{~cm}^{3} \mathrm{~g}^{-1}\right)\end{array}$ & $\begin{array}{c}\mathrm{D}_{\mathrm{BJH}}{ }^{3} \\
(\mathrm{~nm})\end{array}$ & $\begin{array}{c}\mathrm{D}_{\text {ave, BET }}{ }^{4} \\
(\mathrm{~nm})\end{array}$ \\
& & & & & \\
\hline
\end{tabular}




\begin{tabular}{|c|c|c|c|c|c|c|}
\hline SA & 857.2 & 1275.5 & $1082.5^{a}$ & $1.324^{a}$ & $4.89^{a}$ & 5.90 \\
& & & $1172.7^{d}$ & $1.297^{d}$ & $4.42^{d}$ & \\
\hline \multirow{2}{*}{$\mathrm{GA}$} & \multirow{2}{*}{802.7} & \multirow{2}{*}{1208.1} & $1008.3^{a}$ & $1.357^{a}$ & $5.38^{a}$ & 6.58 \\
& & & $1152.9^{d}$ & $1.348^{d}$ & $4.68^{d}$ & \\
\hline
\end{tabular}

${ }^{1} \mathrm{BJH}$ adsorption $(a)$ and desorption $(d)$ cumulative surface area of pores

${ }^{2} \mathrm{BJH}$ adsorption $(a)$ and desorption $(d)$ cumulative pore volume of pores

${ }^{3} \mathrm{BJH}$ adsorption $(a)$ and desorption $(d)$ average pore diameter (4V/A)

${ }^{4}$ Average Pore Diameter (4V/A by BET)

SEM images of G, GO, SA, and GA are displayed in Figure 9 (A-D). According to the images (A and B), flat layers of $\mathrm{G}$ are wrinkled during the oxidation process and lots of curvatures are appeared. Spherical particles with uniform size distribution in the aggregated spongy form, which is characteristics of aerogel materials [43, 83-84], are observed for SA (Figure 9 (C)). Interestingly, spongy silica aerogel network formation at the surface of graphene layers can easily be observed in the GA image (Figure 9 (D)). 

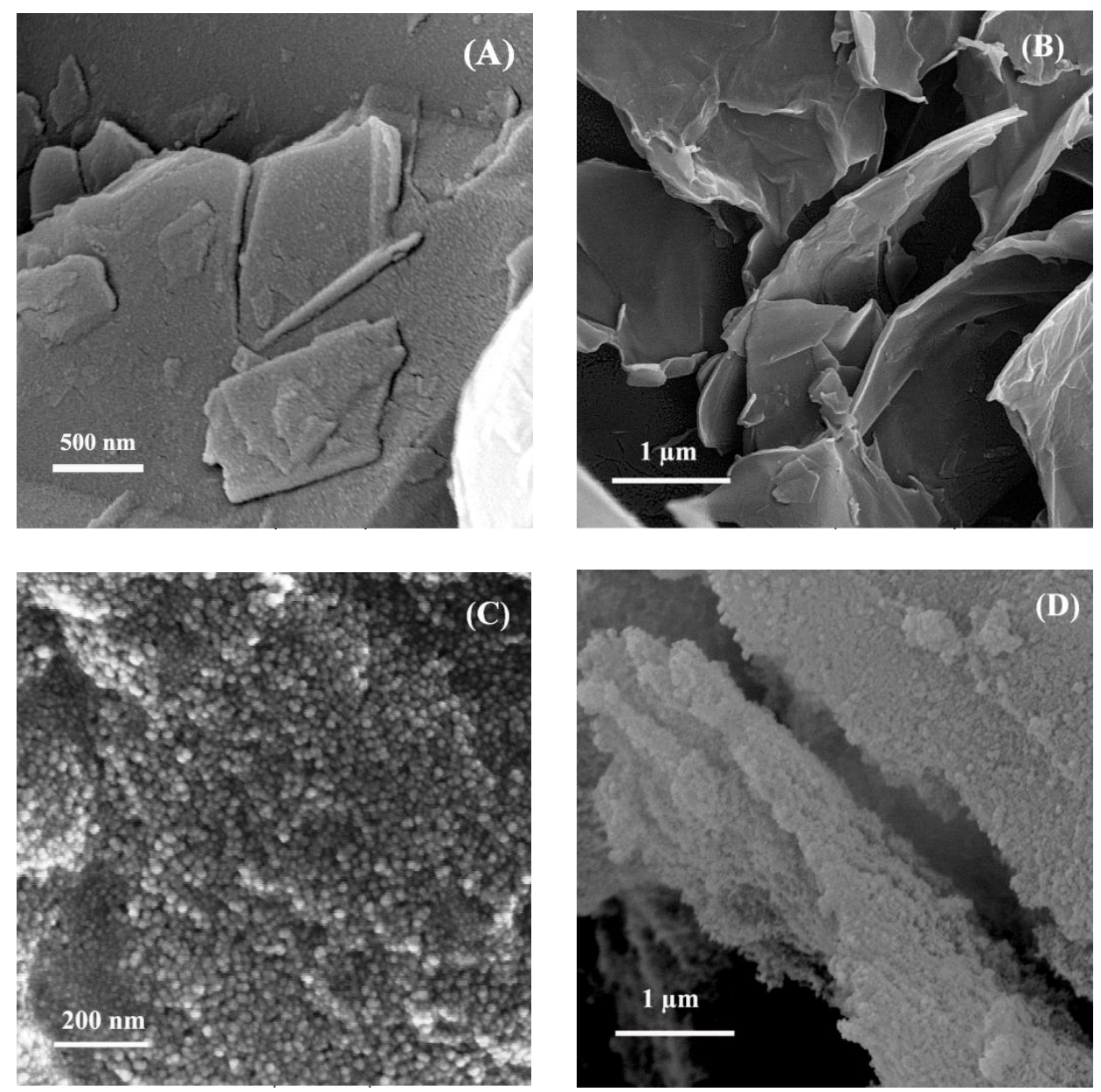

Figure 9- SEM images of (A) G, (B) GO, (C) SA, and (D) GA.

TEM images of G, GO, and GA are shown in Figure 10 (A-D). According to the images (A and B), G and GO are two-dimensional layers, where flat surface of $\mathrm{G}$ is converted to a wrinkled surface with lots of creases and foldings in GO, as also shown in SEM images. Figures 10 (C) and (D) show the micrographs for GA. Silica aerogel network in the presence of silica aerogelcoated graphene layers can easily be observed in the Figures 10 (C). Accordingly, silica aerogel has porous structure; whereas, graphene layers are much larger than the pores in silica aerogel. However, Figures 10 (D) only shows a graphene layer with homogeneous distribution of mesoporous silica aerogel particles. Similar results are reported by Chandrasekaran et al. in TEM micrographs of silica aerogel attached-graphene layers [85]. They obtained their product through 
the reaction of amine groups present in the silica aerogel network and carboxylic acid groups at the edge of GO layers.
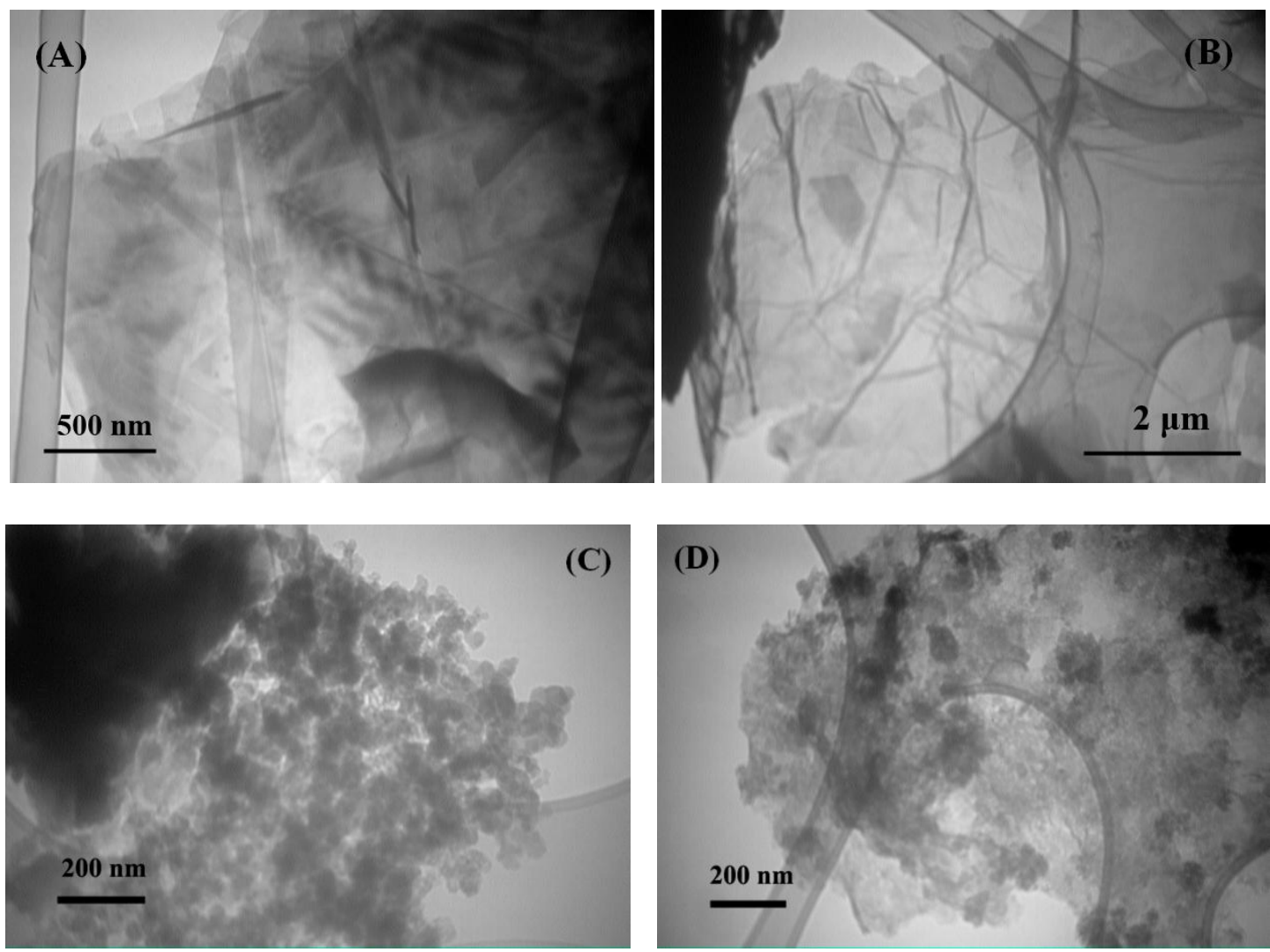

Figure 10- TEM images of (A) G, (B) GO, and (C and D) GA

\section{Conclusions}

Graphene oxide modified with furfuryl alcohol and APTES (GOFASi) was used in two separate ways for preparation of novolac resin nanohybrids. In the first procedure, GA was obtained by incorporation of GOFASi into silica aerogel network by using TEOS. Then, GA was used as an additive in novolac resin matrix. In the second procedure, incorporation of novolac resin and graphene layers into a hybrid material was carried out by network formation of GOFASi, GPTES-modified novolac resin, and TEOS. The products obtained from incorporation of GA in the novolac matrix and those obtained by molecular blending followed by crosslinking of 
modified graphene, modified novolac resin, and the silica precursor TEOS, were compared. Successful modification of GO by furfuryl alcohol and APTES moieties was confirmed by FTIR bands of furan rings and Si-O stretching and also XPS bands for N 1s, Si 2p, and Si 2s. Raman $\mathrm{I}_{\mathrm{D}} / \mathrm{I}_{\mathrm{G}}$ values for GOFA and GOFASi (1.19 and 1.03) show that GO layers are partially reduced upon the functionalization processes. Fading of $2 \mathrm{D}$ and $\mathrm{G}$ bands, sever decrease of $\mathrm{D}$ band intensity, and also appearance of some peaks at below $1000 \mathrm{~cm}^{-1}$ in GA Raman spectrum show that layered structure of graphene is destroyed as a results of aerogel network formation. Expansion of interlayer spacing of GO by every modification process is clearly observed in XRD patterns. GA shows a broad peak at diffraction angle of $21.16^{\circ}$ indicating the poor ordering of layers along their stacking direction. The char yields of about $41.46 \%$ for GOFA and $47.33 \%$ for GOFASi at $700{ }^{\circ} \mathrm{C}$ (for comparison: char yield of neat GO: 37\%) are related to the decomposition of furfuryl alcohol and APTES and also the remained oxygen functionalities. Weight loss and its derivative thermograms for GA are different from the ones of GO and modified GO as result of hybrid network formation. Char yield for the novolac resin is increased to $60.65 \%$ by the addition of $0.5 \mathrm{wt} \%$ of GA. However, the preparation of the novolac/GOFASi/silica hybrid resin via molecular blending followed by crosslinking results in a much higher char value of $70.58 \%$ in the presence of 1 wt $\%$ of GOFASi. Interestingly, incorporation of graphene layers into the aerogel network results in higher cumulative pore volume values and also broader pore diameter distribution curve with a larger peak point value. The pore sizes of SA and GA range from 2 to about $100 \mathrm{~nm}$; however, size of a large number of pores is between 2 and $10 \mathrm{~nm}$ in both of them. Pores are increased in diameter and they become more heterogeneous in size in the presence of graphene layers. 


\section{Acknowledgments}

Iran National Science Foundation (INSF) is greatly appreciated for its financial support (Grant Number: 93030431).

\section{References}

[1]. Wen J, Wilkes GL. Organic/Inorganic Hybrid Network Materials by the Sol-Gel Approach. Chem Mater 1996;8(8):1667-81.

[2]. Schubert U, Huesing N, Lorenz A. Hybrid Inorganic-Organic Materials by Sol-Gel Processing of Organofunctional Metal Alkoxides. Chem Mater 1995;7(11):2010-27.

[3]. Schmidt H, Jonschker G, Goedicke S, Mennig M. The Sol-Gel Process as a Basic Technology for Nanoparticle-Dispersed Inorganic-Organic Composites. J Sol-Gel Sci Technol 2000;19:39-51.

[4]. Reim M, Körner W, Manara J, Korder S, Arduini-Schuster M, Ebert HP, Fricke J. Silica aerogel granulate material for thermal insulation and daylighting. Solar Energy 2005;79:131-9.

[5]. Gibiat V, Lefeuvre O, Woignier T, Pelous J, Phalippou J. Acoustic properties and potential applications of silica aerogels. J Non-Crystalline Solids 1995;186:244-55.

[6]. Chiang CL, Ma CCM, Wu DL, Kuan HC. Preparation, Characterization, and Properties of Novolac-Type Phenolic/SiO $\mathrm{Si}_{2}$ Hybrid Organic-Inorganic Nanocomposite Materials by SolGel Method. J Polym Sci Part A: Polym Chem 2003;41:905-3.

[7]. Li J, Wang F, Liu C. Tri-isocyanate reinforced graphene aerogel and its use for crude oil adsorption. J Colloid Interf Sci 2012;382:13-6. 
[8]. Zhang Y, Shen Y, Han D, Wang Z, Song J, Niu L. Reinforcement of silica with singlewalled carbon nanotubes through covalent functionalization. J Mater Chem 2006;16:45927.

[9]. Yang H, Li F, Shan C, Han D, Zhang Q, Niu L, Ivaska A. Covalent functionalization of chemically converted graphene sheets via silane and its reinforcement. J Mater Chem 2009;19:4632-8.

[10]. Sun X, Cheng P, Wang H, Xu H, Dang L, Liu Z, Lei Z. Activation of graphene aerogel with phosphoric acid for enhanced electrocapacitive performance. Carbon 2015;92;1-10.

[11]. Xu Y, Sheng K, Li C, Shi G. Self-assembled graphene hydrogel via a one-step hydrothermal process. ACS Nano 2010;4:4324-30.

[12]. Baumann TF, Worsley MA, Han TYJ, Satcher JH. High surface area carbon aerogel monoliths with hierarchical porosity. J Non-Crystalline Solids 2008;354;3513-5.

[13]. Fan Z, Gong F, Nguyen ST, Hai M. Duong Advanced multifunctional graphene aerogelPoly (methyl methacrylate) composites: Experiments and modeling. Carbon 2015;81:396404.

[14]. Chen W, Yan L. In situ self-assembly of mild chemical reduction graphene for threedimensional architectures. Nanoscale 2011;3(8):3132-7.

[15]. Tang G, Jiang ZG, Li X, Zhang HB, Dasari A, Yu ZZ. Three dimensional graphene aerogels, and their electrically conductive composites. Carbon 2014;77:592-9.

[16]. Dong L, Yang Q, Xu C, Li Y, Yang D, Hou F, Yin H, Kang F. Facile preparation of carbon nanotube aerogels with controlled hierarchical microstructures and versatile performance. Carbon 2015;90:164-71. 
[17]. Kohlmeyer RR, Lor M, Deng J, Liu H, Chen J. Preparation of stable carbon nanotube aerogels with high electrical conductivity and porosity. Carbon 2011;49:2352-61.

[18]. Kabiri S, Tran DNH, Altalhi T, Losic D, Outstanding adsorption performance of graphene-carbon nanotube aerogels for continuous oil removal. Carbon 2014;80:523-3.

[19]. Sui Z, Meng Q, Zhang X, Ma R, Cao B. Green synthesis of carbon nanotube-graphene hybrid aerogels and their use as versatile agents for water purification. J Mater Chem 2012;22:8767-71.

[20]. Liu Y, Jing X. Pyrolysis and structure of hyperbranched polyborate modified phenolic resins. Carbon 2007;45:1965-1971.

[21]. Xu P, Jing X. Pyrolysis of Hyperbranched Polyborate Modified Phenolic Resin. Polym Eng Sci 2010;50:1382-8.

[22]. Xu P, Jing X. High carbon yield thermoset resin based on phenolic resin, hyperbranched polyborate, and paraformaldehyde. Polym Adv Technol 2011;22:2592-5.

[23]. Wang S, Jing X, Wang Y, Si J. High char yield of aryl boron-containing phenolic resins: The effect of phenylboronic acid on the thermal stability and carbonization of phenolic resins. Polym Degrad Stab 2014;99:1-11.

[24]. Hsiue GH, Shiao SJ, Wei HF, Kuo WJ, Sha YA. Novel phosphorus-containing dicyclopentadiene-modified phenolic resins for flame-retardancy applications. J Appl Polym Sci 2001;79:342-9.

[25]. Haraguchi K, Usami Y, Yamamura K, Matsumoto S. Morphological investigation of hybrid materials composed of phenolic resin and silica prepared by in situ polymerization. Polymer 1998;39:6243-50. 
[26]. Lin JM, Ma CC, Wang FY, Wu HD, Kuang SC. Thermal, mechanical, and morphological properties of phenolic resin/silica hybrid creamers. J Polym Sci Part B: Polym Phys 2000;38:1699-706.

[27]. Roghani-Mamaqani H, Haddadi-Asl V, Mortezaei M, Khezri K. Furfuryl alcohol functionalized graphene nanosheets for synthesis of high carbon yield novolak composites. J Appl Polym Sci 2014;131:40273.

[28]. Zhao X, Li Y, Wang J, Ouyang Z, Li J, Wei G, Su Z. Interactive Oxidation-Reduction Reaction for the in Situ Synthesis of Graphene-Phenol Formaldehyde Composites with Enhanced Properties. ACS Appl Mater Interfaces 2014;6:4254-63.

[29]. Cui BJ, Yan Y, Liu J, Wu Q. Phenolic Resin-MWNT Nanocomposites Prepared through an in situ Polymerization Method. Polym J 2008;40(11):1067-73.

[30]. Liu L, Ye Z. Effects of modified multi-walled carbon nanotubes on the curing behavior and thermal stability of boron phenolic resin. Polym Degrad Stab 2009;94:1972-78.

[31]. Marcano DC, Kosynkin DV, Berlin JM, Sinitskii A, Sun Z, Slesarev A, Alemany LB, Lu W, Tour JM. Improved Synthesis of Graphene Oxide. ACS Nano 2010;4:4806-14.

[32]. Pan Y, Bao H, Sahoo NG, Wu T, Li L. Water-Soluble Poly(N-isopropylacrylamide)Graphene Sheets Synthesized via Click Chemistry for Drug Delivery. Adv Func Mater 2011;21:2754-63.

[33]. Roghani-Mamaqani H, Haddadi-Asl V, Khezri K, Salami-Kalajahi M. Polystyrene-grafted graphene nanoplatelets with various graft densities by atom transfer radical polymerization from the edge carboxyl groups. RSC Adv 2014;4:24439-52. 
[34]. Roghani-Mamaqani H, Haddadi-Asl V, Khezri K, Salami-Kalajahi M. Edge-functionalized graphene nanoplatelets with polystyrene by atom transfer radical polymerization: grafting through carboxyl groups. Polym Int 2014;63:1912-23.

[35]. Roghani-Mamaqani H, Haddadi-Asl V, Sobhkhiz Z, Ghaderi-Ghahfarrokhi M. Grafting poly (methyl methacrylate) from azo-functionalized graphene nanolayers via reverse atom transfer radical polymerization. Colloid Polym Sci 2015;293:735-50.

[36]. Roghani-Mamaqani H. Surface-initiated ATRP of styrene from epoxy groups of graphene nanolayers: twofold polystyrene chains and various graft densities. RSC Adv 2015;5:53357-68.

[37]. Gonzalez R, Figueroa JM, Gonzalez H. Furfuryl alcohol polymerisation by iodine in methylene chloride. Europ Polym J 2002;38:287-97.

[38]. Men XH, Zhang ZZ, Song HJ, Wang K, Jiang W. Functionalization of carbon nanotubes to improve the tribological properties of poly(furfuryl alcohol) composite coatings. Compos Sci Technol 2008;68;1042-9.

[39]. Wu C, Huang X, Wang G, Wu X, Yang K, Li S, Jiang P. Hyperbranched-polymer functionalization of graphene sheets for enhanced mechanical and dielectric properties of polyurethane composites. J Mater Chem 2012;22:7010-9.

[40]. Li W, Tang XZ, Zhang HB, Jiang ZG, Yu ZZ, Du XS, Mai YW. Simultaneous surface functionalization and reduction of graphene oxide with octadecylamine for electrically conductive polystyrene composites. Carbon 2011;49:4724-30.

[41]. Deng Y, Zhang JZ, Li Y, Hu J, Yang D, Huang X. Thermoresponsive graphene oxidePNIPAM nanocomposites with controllable grafting polymer chains via moderate in situ SET-LRP. J Polym Sci Part A: Polym Chem 2012;50:4451-8. 
[42]. Pu X, Zhang HB, Li X, Gui C, Yu ZZ. Thermally conductive and electrically insulating epoxy nanocomposites with silica-coated graphene. RSC Adv 2014;4:15297-303.

[43]. Mirshafiei-Langari SA, Haddadi-Asl V, Roghani-Mamaqani H, Sobani M, Khezri K. Synthesis of Hybrid Free and Nanoporous Silica Aerogel-Anchored Polystyrene Chains via In Situ Atom Transfer Radical Polymerization. Polym Compos 2013;34:1648-54.

[44]. Yuan FY, Zhang HB, Li X, Ma HL, Li XZ, Yu ZZ, In situ chemical reduction and functionalization of graphene oxide for electrically conductive phenol formaldehyde composites. Carbon 2014;68:653-61.

[45]. Li M, Song H, Chen X, Zhou J, Ma Z. Phenolic resin-grafted reduced graphene oxide as a highly stable anode material for lithium ion batteries. Phys Chem Chem Phys 2015;17:3250-60.

[46]. Chiang CL, Ma CCM, Wu DL, Kuan HC. Preparation, characterization, and properties of novolac-type phenolic/SiO${ }_{2}$ hybrid organic-inorganic nanocomposite materials by sol-gel method. J Polym Sci Part A: Polym Chem 2003;41:905-13.

[47]. Li Z, Wang R, Young RJ, Deng L, Yang F, Hao L, Jiao W, Liu W. Control of the functionality of graphene oxide for its application in epoxy nanocomposites. Polymer 2013;54:6437-46.

[48]. Yang H, Shan C, Li F, Han D, Zhang Q, Niu L. Covalent functionalization of polydisperse chemically-converted graphene sheets with amine-terminated ionic liquid. Chem Commun $2009 ; 3880-2$.

[49]. Li W, Tang XZ, Zhang HB, Jiang ZG, Yu ZZ, Du XS, Mai YW. Simultaneous surface functionalization and reduction of graphene oxide with octadecylamine for electrically conductive polystyrene composites. Carbon 2011;49:4724-30. 
[50]. Roghani-Mamaqani H, Haddadi-Asl V, Khezri K, Salami-Kalajahi M, Najafi M. Kinetic study of styrene atom transfer radical polymerization from hydroxyl groups of graphene nanoplatelets: Heterogeneities in chains and graft densities. Polym Eng Sci 2015; DOI: 10.1002/pen.24010

[51]. Kim NH, Kuil T, Lee JH. Simultaneous reduction, functionalization and stitching of graphene oxide with ethylenediamine for composites application. J Mater Chem A 2013;1:1349-58.

[52]. Hernandez Y, Nicolosi V, Lotya M, Blighe FM, Sun Z, De S, McGovern IT, Holland B, Byrne M, Gun'Ko YK, Boland JJ, Niraj P, Duesberg G, Krishnamurthy S, Goodhue R, Hutchison J, Scardaci V, Ferrari AC, Coleman JN. High-yield production of graphene by liquid-phase exfoliation of graphite. Nat Nanotechnol 2008;3: 563-8.

[53]. Roghani-Mamaqani H, Haddadi-Asl V, Khezri K, Zeinali E, Salami-Kalajahi M. In situ Atom Transfer Radical Polymerization of Styrene to In-plane Functionalize Graphene Nanolayers: Grafting through Hydroxyl Groups. J Polym Res 2014;21:333.

[54]. Roghani-Mamaqani H, Haddadi-Asl V. In-Plane Functionalizing Graphene Nanolayers with Polystyrene by Atom Transfer Radical Polymerization: Grafting from Hydroxyl Groups. Polym Compos 2014;35:386-95.

[55]. Miroshnikov Y, Grinbom G, Gershinsky G, Nessim GD, Zitoun D. Do we need covalent bonding of Si nanoparticles on graphene oxide for Li-ion batteries?. Faraday Discuss 2014;173:391-402.

[56]. Chen S, Bao P, Huang X, Sun B, Wang G. Hierarchical 3D mesoporous silicon@graphene nanoarchitectures for lithium ion batteries with superior performance. Nano Res 2014;7(1):85-94. 
[57]. Zhang M, Gao B, Cao X, Yang L. Synthesis of a multifunctional graphene-carbon nanotube aerogel and its strong adsorption of lead from aqueous solution. RSC Adv 2013;3:21099-105.

[58]. Adhikari PD, Jeon S, Cha MJ, Jung DS, Kim Y, Park CY. Immobilization of carbon nanotubes on functionalized graphene film grown by chemical vapor deposition and characterization of the hybrid material. Sci Technol Adv Mater 2014;15:015007.

[59]. Qi X, Zhai G, Liang J, Ma S, Liuad X, Xu B. Preparation and characterization of SiC@CNT coaxial nanocables using CNTs as a template. Cryst Eng Comm 2014;16:969703.

[60]. Wasyluk J, Perova TS, Kukushkin SA, Osipov AV, Feoktistov NA, Grudinkin SA. Raman Investigation of Different Polytypes in SiC Thin Films Grown by Solid-Gas Phase Epitaxy on Si (111) and 6H-SiC Substrates. Mater Sci Forum 2010;645-648:359-62.

[61]. McAllister MJ, Li JL, Adamson DH, Schniepp HC, Abdala AA, Liu J, et al. Single sheet functionalized graphene by oxidation and thermal expansion of graphite. Chem Mater 2007;19:4396-404.

[62]. Liu S, Tian J, Wang L, Sun X. Microwave-assisted rapid synthesis of Ag nanoparticles/graphene nanosheet composites and their application for hydrogen peroxide detection. J Nanopart Res 2011;13(10):4539-48.

[63]. Wang H, Yi H, Chen X, Wang X. One-step strategy to three-dimensional graphene/ $\mathrm{VO}_{2}$ nanobelt composite hydrogels for high performance supercapacitors. J Mater Chem A 2014;2:1165-73.

[64]. Lei Z, Yan Y, Feng J, Wu J, Huang G, Li X, Xing W, Zhao L. Enhanced power factor within graphene hybridized carbon aerogels. RSC Adv 2015;5:25650-6. 
[65]. Zhang X, Sui Z, Xu B, Yue S, Luo Y, Zhan W, Liuc B. Mechanically strong and highly conductive graphene aerogel and its use as electrodes for electrochemical power sources. J Mater Chem 2011;21:6494-7.

[66]. Qian Y, Wei P, Jiang P, Liu J. Preparation of halogen-free flame retardant hybrid paraffin composites as thermal energy storage materials by in situ sol-gel process. Sol Energy Mater Sol Cells 2012;107:13-9.

[67]. Wang Z, Wei P, Qian Y, Liu J. The synthesis of a novel graphene-based inorganic-organic hybrid flame retardant and its application in epoxy resin. Composites: Part B 2014;60:3419.

[68]. Yang SB, Feng XL, Ivanovici S, Mullen K. Fabrication of Graphene-Encapsulated Oxide Nanoparticles: Towards High-Performance Anode Materials for Lithium Storage. Angew Chem Int Ed 2010;49:8408-11.

[69]. Chen L, Wang X, Zhang X, Zhang H. 3D porous and redox-active prussian blue-ingraphene aerogels for highly efficient electrochemical detection of $\mathrm{H}_{2} \mathrm{O}_{2}$. J Mater Chem 2012;22:22090-6.

[70]. Cheng WY, Wang CC, Lu SY. Graphene aerogels as a highly efficient counter electrode material for dye-sensitized solar cells. Carbon 2013;54:291-9.

[71]. Dante RC, Santamaria DA, Gil JM. Crosslinking and Thermal Stability of Thermosets Based on Novolak and Melamine. J Appl Polym Sci 2009;114:4059-65.

[72]. Jung I, Dikin D, Park S, Cai W, Mielke SL, Ruoff RS. Effect of water vapor on electrical properties of individual reduced graphene oxide sheets. J Phys Chem C 2008;112:20264-8. 
[73]. Roghani-Mamaqani H, Haddadi-Asl V, Khezri K, Salami-Kalajahi M, Najafi M, Sobani $M$, et al., Confinement effect of graphene nanoplatelets on atom transfer radical polymerization of styrene: grafting through hydroxyl groups. Iran Polym J 2015;24:51-62.

[74]. Stankovich S, Dikin DA, Piner RD, Kohlhaas KA, Kleinhammes A, Jia Y, Wu Y, Nguyen SBT, Ruoff RS. Synthesis of graphene-based nanosheets via chemical reduction of exfoliated graphite oxide. Carbon 2007;45:1558-65.

[75]. Ngo VG, Bressy C, Leroux C, Margaillan A. Synthesis of hybrid $\mathrm{TiO}_{2}$ nanoparticles with well-defined poly(methyl methacrylate) and poly(tert-butyldimethylsilyl methacrylate) via the RAFT process. Polymer 2009;50:3095-102.

[76]. Roghani-Mamaqani H, Haddadi-Asl V, Ghaderi-Ghahfarrokhi M, Sobhkhiz Z. Reverse atom transfer radical polymerization of methyl methacrylate in the presence of Azofunctionalized carbon nanotubes: a grafting from approach. Colloid Polym Sci 2014;292:2971-81.

[77]. Wang S, Jing X, Wang Y, Si J. Synthesis and characterization of novel phenolic resins containing aryl-boron backbone and their utilization in polymeric composites with improved thermal and mechanical properties. Polym Adv Technol 2014;25:152-9.

[78]. Brunauer S, Emmett PH, Teller E. Adsorption of gases in multimolecular layers. J Am Chem Soc 1938;60:309-19.

[79]. Mirshafiei-Langari SA, Haddadi-Asl V, Roghani-Mamaqani H, Sobani M, Khezri K. In Situ Atom Transfer Radical Polymerization of Styrene in the Presence of Nanoporous Silica Aerogel: Kinetic Study and Investigation of Thermal Properties. J Polym Res 2013;20:163. 
[80]. Barrett EP, Joyner LG, Halenda PP. The determination of pore volume and area distributions in porous substances: Computations from nitrogen isotherms. J Amer Chem Soc $1951 ; 73: 373-80$.

[81]. Plonska-Brzezinska ME, Molina-Ontoria A, Echegoyen L. Post-modification by lowtemperature annealing of carbon nano-onions in the presence of carbohydrates. Carbon 2014;67:304-17.

[82]. Yamanaka S, Brindley GW. High surface area solids obtained by reaction of montmorillonite with zirconyl chloride. Clays Clay Minerals 1979;27(2):119-24.

[83]. Sobani M, Haddadi-Asl V, Salami-Kalajahi M, Roghani-Mamaqani H, Mirshafiei-Langari SA, Khezri K. "Grafting through" approach for synthesis of polystyrene/silica aerogel nanocomposites by in situ reversible addition-fragmentation chain transfer polymerization. J Sol-Gel Sci Technol 2013;66:337-44.

[84]. Sobani M, Haddadi-Asl V, Mirshafiei-Langari SA, Salami-Kalajahi M, RoghaniMamaqani H, Khezri K, A kinetics study on the in situ reversible addition-fragmentation chain transfer and free radical polymerization of styrene in presence of silica aerogel nanoporous particles. Designed Monomers Polymers 2014;17:245-54.

[85]. Chandrasekaran N, Sivabalan S, Prathap A, Mohan S, Jagannathan R. Delocalization of electronic states in graphene oxide stabilised mesoporous silica nanoparticles revealed using photoluminescence. RSC Adv 2014;4:17879-83. 